
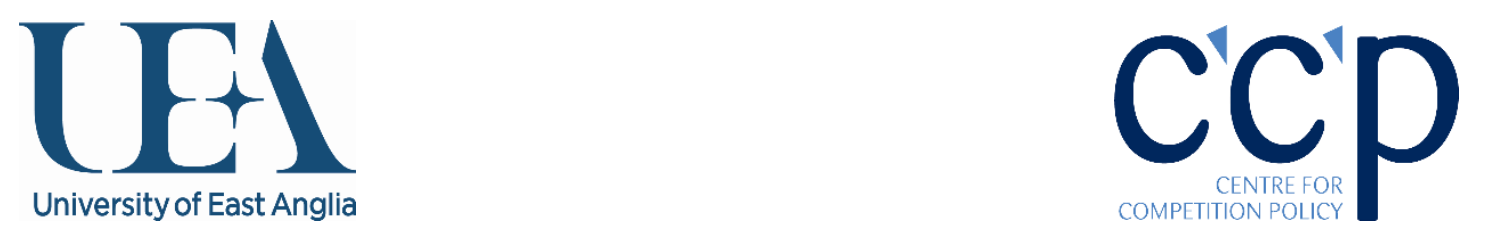

\title{
Post-Cartel Tacit Collusion: Determinants, Consequences, and Prevention
}

\author{
Subhasish M. Chowdhury and Carsten J. Crede \\ Centre for Competition Policy \\ Centre for Behavioural and Experimental Social Science and \\ School of Economics \\ University of East Anglia
}

CCP Working Paper 15-1 v2

\begin{abstract}
We experimentally investigate the attributes and effects of post-cartel tacit collusion (PCTC) as well as policy measures aimed at its prevention. PCTC occurs irrespective of the absence or presence of an antitrust authority and in different competition regimes. PCTC is determined both by collusive price hysteresis and learning about cartel partners' characteristics and strategies. As a result, it is strongly related with the preceding cartel success. The estimation of cartel overcharges, an important factor in litigation, is found out to be biased downwards in the presence of PCTC. As a policy note, we show that debarment of managers involved in cartels from the market can prevent PCTC.
\end{abstract}

Contact Details:

Carsten Crede

c.crede@uea.ac.uk 


\title{
Post-Cartel Tacit Collusion: \\ Determinants, Consequences, and Prevention*
}

\author{
Subhasish M. Chowdhury and Carsten J. Crede \\ School of Economics, Centre for Behavioural and Experimental Social Science, and Centre for \\ Competition Policy, University of East Anglia, Norwich NR4 7TJ, UK
}

November 2, 2015

\begin{abstract}
We experimentally investigate the determinants of post-cartel tacit collusion (PCTC) and the effects of PCTC on market outcomes as well as potential policy measures aimed at its prevention. PCTC occurs robustly across various competition regimes and is determined both by collusive price hysteresis and learning about cartel partners' characteristics and strategies. As a result, it is strongly related with the preceding cartel success. The estimation of cartel overcharges, an important factor in litigation, is found out to be biased downwards in the presence of PCTC. As a policy note, we show that removal of managers involved in cartels from the market can prevent PCTC.
\end{abstract}

JEL Classification: C91; D03; D43; L13; L41

Keywords: tacit collusion; antitrust; cartels; price hysteresis; experiment

\footnotetext{
*Corresponding author: Carsten Crede (c.crede@uea.ac.uk).

We thank David Angenendt, Maria Bigoni, Steve Davies, Luke Garrod, Joris Gillet, Morten Hviid, Kai-Uwe Kühn, Matt Olczak, Sander Onderstal, Sigrid Suetens, Fred Wandschneider, Alexandra Zaby, participants at the 2015 London Experimental Workshop, the 2015 Spring Meeting of Young Economists, the 2015 Mannheim Centre for Competition and Innovation conference, the 2014 London Experimental Economics PhD Workshop, as well as seminar participants at the University of East Anglia for helpful comments. Any remaining errors are our own.
} 


\section{Introduction}

No formal agreement is necessary to constitute an unlawful conspiracy. Often crimes are a matter of inference deduced from the acts of the person accused and done in pursuance of a criminal purpose [...] Where the circumstances are such [...] that the conspirators had a unity or purpose or a common design and understanding [...], the conclusion that a conspiracy is established is justified (U.S. Supreme Court in American Tobacco Co. v. United States, 328 U.S. 781 (1946)).

The deterrence of cartels, "the supreme evil of antitrust"1, is a top priority of most antitrust authorities around the world. This deterrence is based fundamentally upon continuous and correct enforcement through fines by the authorities and through compensatory damages awarded by courts in private damage litigation. The fines and damages can only deter cartels if they are based on the conspiring firms' gains from the cartel. The estimation of these gains is a problem in particular in private damage litigation, in which economic expert witnesses need to provide a precise estimate of cartel overcharges. However, if firms engage in post-cartel tacit collusion (PCTC) to continue to earn supercompetitive profits, the cartel overcharges might be underestimated and deterrence as well as proper compensation will not be achieved. This is a problem in some of the price-based approaches commonly used in court cases in which post-cartel periods might be used as competitive counterfactuals and PCTC is not accounted for (see, e.g., Harrington, 2004; Davis and Garcés, 2009). Yet, little is known under which circumstances PCTC might occur and how to prevent it. With private damage litigation based on precise cartel damage estimation in cartel cases being on the rise, a better understanding of the determinants, consequences, and tools for the prevention of PCTC is now needed more than ever. $^{2}$ In this study we aim to fill in this important gap both at an academic as well as at a policy level.

PCTC has been observed or at least suspected in a number of cases and based on different methodologies: Harrington (2004) provides a theoretical model, Fonseca and Normann (2012) experimental results, and Connor (1998), Connor (2001), Roos (2006), and Ordóñez-de Haro and Torres (2014) empirical observations that point towards the occurrence of tacit collusion after the end of cartels. Connor (1998) notes that prices in the citric acid industry did not decline significantly in the 18 months after cartel breakdown. However, it is not certain whether this observation was triggered by increases in input prices or by tacit collusion. Similar suspicion arises in Connor (2001) and Roos (2006) for the lysine cartel. Roos (2006) provides two potential explanations for the lack of post-cartel price reductions in the lysine industry, in which prices actually rose after the detection of the cartel. On the one hand, the conspirators could have learned enough about each other's behavior and features and several years of explicit

\footnotetext{
${ }^{1}$ Verizon Communications v. Law Offices of Curtis V. Trinko, 540 U.S. 398, 408 (2004).

${ }^{2}$ In the last 30 years, private damage litigation grew significantly in the United States with $\sim 90 \%$ of all cartel cases being based on private action representing an important source of cartel deterrence (Wils, 2003; Lande and Davis, 2008). In December 2014, the European Commission released the new Directive on Antitrust Damage Actions indicating a future growth of importance of private actions against cartels in Europe as well.
} 
communication and cooperation might have enabled them to collude tacitly. Knowing that communication to dissolve disputes was no longer possible after breakdown, the firms might have been particularly careful to prevent a price war. On the other hand, the firms could have continued to set collusive prices to reduce fines to be paid under the U.S. antitrust sentencing guidelines. Harrington (2004) shows that firms have the strategic interest to keep the prices high after cartel breakdown during litigation, such that overcharge estimates based on post-cartel prices underestimate the true harm caused by the cartel. Erutku (2012) provides empirical evidence for this idea. Ordóñez-de Haro and Torres (2014) examine the breakup of several Spanish food cartels that relied on the signals of trade associations. Significant levels of price hysteresis (i.e., prices remained high and were subject to a reduced variance) after antitrust intervention can be observed in most of the cartels and the firms could have been sticking to past signals received from their trade associations. Fonseca and Normann (2012) provide experimental evidence for the existence of tacit collusion after periods of explicit communication. ${ }^{3}$ They also point out that the level of tacit collusion declines over time and with the number of competitors.

Although these studies provide suggestions regarding the existence and potential sources of PCTC, these have not yet been tested. This renders it hard to derive policy implications aimed at preventing wrong cartel overcharge estimates or to implement measures against the occurrence of PCTC. Therefore, the aim of this study is to investigate the incidence and identify the determinants of tacit collusion after periods of explicit communication. ${ }^{4}$ In this endeavor, we pursue to answer the following research questions: (1) Is the existence of PCTC a common phenomenon robust to differences of competition laws? (2) What are the determinants of PCTC? (3) What consequences does PCTC have for attempts to estimate cartel overcharges? (4) Can policy measures be implemented to prevent or reduce PCTC?

We use experiments to investigate these questions. This approach allows for an analysis of the marginal contribution of different market characteristics to tacit collusion in a controlled environment. Lack of data prevents pursuing a similar exercise in the field. To our knowledge, this article provides the first experiment to systematically investigate the driving factors, related consequences, and possible preventive measures with respect to PCTC. Results show that PCTC is a robust phenomenon across competition regimes. Learning about other players' types through successful cartel formation turns out to be one of the determinants of PCTC. It is found that the cartel damage estimates may indeed be biased if PCTC is not accounted for. Removal of managers engaged in cartels is proposed and successfully tested as a measure to prevent PCTC.

The paper proceeds as follows. A simple theoretical model is set up in Section 2 that explains PCTC as a result of firms learning about each other in periods of collusion. In Section 3, the experiment is presented with respect to its procedure and design. Based on findings of previous

\footnotetext{
${ }^{3}$ Isaac and Walker (1988) are the first to test the effects of communication on coordination after communication is disallowed in public goods experiments. They find that preceding communication significantly reduces freeriding in periods without communication, and that the effect diminishes over time.

${ }^{4}$ Therefore, we are not interested in pure tacit collusion, i.e., collusion without any communication (see, e.g., Ivaldi et al., 2003; Martin, 2006).
} 
literature, hypotheses are formulated that motivate the succeeding analysis. The results are presented in Section 4: the transition from cartels to tacit collusion is analyzed in Section 4.1, the sources of PCTC are determined in Section 4.2 and the implications with respect to cartel overcharge estimation are discussed in Section 4.3. Section 5 concludes.

\section{Sources of post-cartel tacit collusion}

\subsection{Background}

Despite the important legal difference between explicit and tacit collusion, the standard theory of collusion does not differentiate between the two. Only recently have scholars begun to close this gap in the theory (Martin, 2006; Harrington, 2012; Vermeulen et al., 2013). An important function of communication in collusion is that it reduces uncertainty about present and past actions (Mouraviev, 2006). Throughout the paper, we refer to explicit communication as communication, and implicit communication as price signalling. Although there are other forms of implicit communication, signalling with price choice is the only means to express intentions outside of communication in the experiment. ${ }^{5}$ Despite the importance of communication for collusion, the aforementioned empirical evidence indicates that tacit collusion can be sustained after periods of communication. This suggests that communication has intertemporal effects on collusion: it might not only reduce uncertainty in the period it is used, but also in the periods afterwards. PCTC then can be induced through two distinct channels. ${ }^{6}$ First, former cartelists can try not to risk breaking up former collusion by abstaining from significant price reductions in the spirit of Chamberlin (1933). We refer to this source for tacit collusion as collusive price hysteresis. A prime example for this source of tacit collusion are the Spanish food cartels observed by Ordóñez-de Haro and Torres (2014). Second, past actions in periods with communication allow firms to learn about each others' types in terms of discount factors and strategies: given successful explicit collusion, the expected profitability of playing collusive strategies in the post-cartel periods increases. We refer to this effect as learning in cartels. Having observed that the other firms were very likely to collude before indicating patience with respect to the incentive compatibility constraint, the likelihood of such behavior for the current period is high. This argument is provided by Roos (2006) as one possible explanation for the observed tacit collusion in the lysine industry after the cartel breakdown. In other words,

\footnotetext{
${ }^{5}$ Price signalling has long been suspected to provide a significant means to facilitate collusion. A prominent example is the U.S. Department of Justice's investigation of the Airline Tariff Publishing Company set up by major U.S. airlines in the early 1990s. The airlines were suspected to fix prices by releasing non-binding announcements of price changes prior to their implementation (Borenstein, 2004). Rabin (1993) provides a game-theoretic explanation for signalling in prisoner-dilemma games, in which subjects can alter outcomes when subjects react to perceived motives of other players that are inferred from their actions. Experimental evidence of signalling is provided by Holt and Davis (1990) and Cason (1995). They find that some firms engage in price signalling and profit from it, but this effect diminishes over time. However, Davis et al. (2010) find no positive effect of price signalling on market prices is found in posted-offer markets.

${ }^{6}$ In the long run, firms could also try to engage in intensified merger activity (Davies et al., 2014).
} 
learning that other firms have high discount factors and are willing to collude by means of repeated communication and successful collusion reduces a firm's uncertainty. Thus, PCTC can be a function of the preceding cartel success. In a game-theoretic sense this occurs if the other firms use these information to update their own strategies in a multi-agent learning environment and learning updates beliefs about other firms' probability to collude (see, e.g., Foster and Young, 2003; Young, 2007). As such, the benefit from renewed communication diminishes over time because uncertainty is reduced already by the history of collusion in the industry.

\subsection{Model}

We focus on periods without communication to explain the effect of learning in cartels on PCTC. Assume that communication ended because the cartel was detected, or that the platform of communication ceases to exist (e.g., a coordinating trade association is dissolved). In such a case, the firms are left with a situation in which they have to consider tacit collusion. However, the firms can rely on their past experience with the other firms when considering whether to behave in a collusive way. A very simple model can be set up to point out how a firm's expectations about other firms' probability of abiding to collusive agreements can affect (tacit) collusion. For simplicity, assume that the firms have a history of collusion and that communication has ended in a way that does not indicate deviation by any firm, including breakdown due to leniency applications. Thus, the model investigates the sustainability of tacit collusion in an industry in which firms inherit information about the history of collusion. ${ }^{7}$

Consider the standard infinitely repeated game collusion model. Without loss of generality, assume a duopoly. In the first period after the end of explicit collusion, firm $i$ considers whether it would like to collude again or cheat. Profits of firm $i$ depend on whether it is cheating on a collusive agreement $\left(\Pi^{d}\right)$ with deviation, having a stable collusive agreement $\left(\Pi^{m}\right)$ that provides a share of the monopoly profits, competition $\left(\Pi^{n}\right)$ with profits based on the Nash equilibrium, or whether it is being cheated upon when sticking to a collusive agreement $\left(\Pi^{c}\right)$. The order of profits is $\Pi^{d}>\Pi^{m}>\Pi^{n}>\Pi^{c}$. Assume that firms can only set two prices, a high price and a low price. Thus, both firms will get $\Pi^{m}$ each if they both set the high price and Nash profits $\Pi^{n}$ if they both deviate from the agreement at the same time. Each firm has an own discount factor of $\delta_{i}$. Further, it is assumed that communication allows the firms to establish collusion again after cheating and periods of punishment. However, once communication is not possible anymore, firms use a grim-trigger strategy.

In each round a firm cannot be certain about the other firm's choice when choosing a strategy: provided that there was collusion before, the opponent can either try to collude again or to cheat. Therefore, each firm has to form expectations with respect to the likelihood that the opponent employs a collusive strategy. Denote the expectations of firm $i$ in period $t$ with regards to firm $j$ sticking to collusion or deviating with probabilities $\lambda_{i t}$ and $\left(1-\lambda_{i t}\right)$, respectively. The

\footnotetext{
${ }^{7} \mathrm{~A}$ thorough version of this model can be found in Appendix A.
} 
variable $t$ measures how many periods have passed since the last period with communication, i.e., the model starts with period $t=1$. The expectations about the other firm's probability of relying on the collusive strategy is a function of a number of factors, $\lambda_{i t}=f\left(S, E\left(\phi_{j}\right), t, \cdot\right)$. Among these factors that determine the beliefs is past cartel success denoted by variable $S$. Define this variable as the share of periods in which collusion was attempted and both firms abided the agreement. The firms inherit this experience from their past explicit collusion. This history of cooperation positively affects their expectations with respect to the likelihood that the other firm uses a collusive strategy in period $t$. Successful collusion establishes trust among competitors and reveals information about each firm's willingness to collude, $\frac{\delta \lambda_{i t}}{\delta S}>0$. Another factor defining beliefs is $\phi_{i}$, which measures an exogenously inherited willingness to collude. Firm $i$ has to form expectations about firm $j$ 's willingness, $\mathrm{E}\left(\phi_{j}\right)$, when considering collusion. Assume that $\frac{\delta \lambda_{i t}}{\delta \phi_{j}}>0$. When thinking about firms as entities controlled by managers, $\phi_{i}$ could be regarded as a manager's risk attitude towards illegal explicit collusion and trust or willingness with respect to cooperation with other firms. Alternatively, $\phi_{i}$ could measure the strength of enforcement of compliance programs within the companies. $\lambda_{i t}$ also depends on time $t$ as uncertainty accumulates over time as the last date of communication moves away further implying $\frac{\partial \lambda_{i t}}{\partial t}<0$. This uncertainty could arise because of different sources, e.g., changing market characteristics over time.

Without loss of generality, we now impose the following simplifying assumption: firms are symmetric in their beliefs, i.e., $E\left(\phi_{i}\right)=E\left(\phi_{j}\right)=\phi, \frac{\partial \lambda_{i t}}{\partial S}=\frac{\partial \lambda_{j t}}{\partial S}$, and $\frac{\partial \lambda_{i t}}{\partial t}=\frac{\partial \lambda_{j t}}{\partial t}$, which imply $\lambda_{i t}=\lambda_{j t}=\lambda_{t}$. If firm $i$ plays a collusive strategy given deviation by the opponent, it will receive $\Pi^{C}$ and both firms revert to Nash competition yielding $\Pi^{n}$ forever afterwards due to the Grim trigger strategy. If it reacts to anticipated deviation by deviating itself, both firms will earn Nash profits $\Pi^{n}$. The incentive compatibility constraint (ICC) for collusion can be expressed as

$$
\lambda_{t} \frac{\Pi^{m}}{1-\delta}+\left(1-\lambda_{t}\right)\left[\Pi^{c}+\frac{\delta}{1-\delta} \Pi^{n}\right] \geq \lambda_{t}\left[\Pi^{d}+\frac{\delta}{1-\delta} \Pi^{n}\right]+\left(1-\lambda_{t}\right) \frac{\Pi^{n}}{1-\delta} .
$$

Rearranging and denoting the critical discount factor for the ICC to hold as $\delta^{\text {crit }}$ yields

$$
\delta^{c r i t} \geq \frac{\lambda_{t}\left(\Pi^{d}-\Pi^{m}\right)+\left(1-\lambda_{t}\right)\left(\Pi^{n}-\Pi^{c}\right)}{\lambda_{t}\left(\Pi^{d}-\Pi^{n}\right)+\left(1-\lambda_{t}\right)\left(\Pi^{n}-\Pi^{c}\right)} .
$$

Notice that the term reduces to the familiar $\delta^{c r i t} \geq\left(\Pi^{d}-\Pi^{m}\right) /\left(\Pi^{d}-\Pi^{n}\right)$ if $\lambda_{t}=1$, and that $\frac{\partial \delta}{\partial \lambda_{t}}<0$ (see, e.g., Belleflamme and Peitz, 2010). In other words, an increase in the expectation that the other firm plays the collusive strategy reduces the incentive compatibility constraint. Therefore, the higher the $\lambda_{t}$ that is inherited from the collusive periods, the less patient the firms have to be to make collusion viable. In the extreme case of $\lambda_{t}=0$, collusion is not possible because this would require $\delta_{i} \geq 1$. Collusion takes place in the industry if $\delta_{i}>\delta^{\text {crit }} \forall i$. In most industries, the distribution of $\delta$ will be such that at least one $\delta_{i}<\delta^{\text {crit }}$ such that communication is required to overcome the critical threshold. However, given that the payoffs of communication erode over time, successfully established PCTC will break down eventually once the discount factor of the least patient firm drops below $\delta^{\text {crit }}$ again. 


\subsection{Implications}

In this framework, PCTC is facilitated by successful preceding communication: experience and learning reduce the incentive compatibility constraint through the effect of $S$ on $\lambda$. This suggests that PCTC might not only be a result of collusive price hysteresis, but also a product of the belief formation related to learning. Provided that the underlying logic holds, the model provides the following implications for the experiment: (1) The transition from explicit to tacit collusion might be common if the same managers are in charge throughout time, (2) on average the magnitude of overcharges created by tacit collusion increases with preceding cartel success through increased probabilities of renewed tacit coordination, (3) tacit collusion should occur irrespective of variations in the competitive regime, e.g., the existence or absence of a competition authority and specific competition laws, (4) ceteris paribus, we should observe more PCTC in environments with a higher incidence of cartels in the preceding communication periods, and (5) PCTC erodes over time. The predictions are discussed in greater detail in the Hypotheses section 3.3.

Another implication arises from the model. Given that learning about other firms and managers drives PCTC, civil sanctions requiring firms engaged in cartels to remove involved managers might lead to a breakdown in collusion: as the positive effect of communication on postcommunication behavior could be linked specifically to the involved personnel, replacement of management could completely eradicate PCTC. Some experimental evidence is provided by Davis et al. (2009), who find that rematching reduces pure tacit collusion in posted-offer markets. Any learning with respect to strategies of a competitor or a rival's manager becomes obsolete the moment key personnel is replaced in the firm. This eliminates the impact of the collusive history on PCTC after the end of communication. As renewed communication is likely to be deemed too risky after the cartel was detected, firms might be unable to engage in explicit collusion. ${ }^{8}$

\section{Experiment}

\subsection{Experimental procedure}

The experiment was conducted between March and November 2014 at the Centre for Behavioral and Experimental Social Science (CBESS) at the University of East Anglia, UK. It was programmed and carried out with z-Tree (Fischbacher, 2007) and the recruitment of subjects was done using ORSEE (Greiner, 2004). The subjects were allocated in groups of three and interacted with the same two other participants throughout the experiment (except for a treatment in which managers are rematched in between). We recruited 228 students without

\footnotetext{
${ }^{8}$ Collusion might still occur when new managers stick to previous cartel prices as a focal point, which is a potential source for tacit collusion not covered in the theoretical model. However, this would require the new managers to simultaneously choose the same strategy without communication, which is not very likely given that communication was needed before to establish a cartel price.
} 
prior experience in oligopoly experiments and from a variety of backgrounds. 36 subjects participated in each treatment to obtain 12 independent market observations. ${ }^{9}$

Subjects were randomly seated in the laboratory at the start of the session. Each participant received a printed copy of the instructions, which were also read aloud by an experimenter at the beginning of the session and displayed on the computer screen. Questions about the instructions could be asked in private by subjects raising their hands calling for an experimenter.

The experiment consisted of two parts. In the first part, each subject's risk preference was tested with a risk elicitation task similar to Holt and Laury (2002). Subjects indicated their choices on their computers, and the outcome of the lottery was determined at the very end of the session. For this, a computerized random draw common to all participants selected the lottery and the option to be paid. In the second part, subjects interacted in markets as described in Section 3.2 for 20 (30 for one treatment) regular periods. Subjects' understanding of the instructions was tested with a questionnaire. ${ }^{10}$ To prevent potential end-game effects and to reflect the infinitely repeated game with discounting, a random stopping rule in the spirit of Dal Bó (2005) was implemented: after the end of the regular periods, in each period there was a 20\% chance that the experiment ends. The experiment ended with subjects filling out an anonymous demographic survey. An example of the instructions can be found in Appendix C.

Sessions lasted between 25 and 50 minutes and subjects were allowed to participate in one session only. Earnings in part one were denoted in British Pounds, whereas earnings in the second part consisted of "experimental points". Each experimental point gained in the market experiment was converted into 15 Pence at the end of the experiment. Payments varied from $£ 5.63$ to $£ 28.90$ with a mean of $£ 11.35$.

\subsection{Experimental design}

A number of studies from the growing body of literature on cartel experiments is relevant for this analysis. Fonseca and Normann (2012) provide experimental evidence for the effect of communication on collusion after the end of communication and point out that the effect's magnitude depends on the number of firms in the market. In their experiment the gains for firms are characterized by an inverted U curve and are highest for markets with four firms. Further, they find that these gains diminish over time. Fonseca and Normann (2014) find a higher level of cartel recidivism for markets with four firms than with duopolies, as four-firm markets profit more from re-engaging in communication after cartel breakdown. These two are the only studies to provide experimental evidence on PCTC. However, they focus on the link between PCTC and the number of firms in the market, and do not investigate the reasons, consequences, or methods for prevention of PCTC.

\footnotetext{
${ }^{9} 42$ subjects participated in the Fine and MRemoval treatments. Therefore, in these treatments 14 independent markets can be observed.

${ }^{10}$ All values used in the questionnaire were randomly and independently determined for each subject to prevent example numbers in the questions to systematically influence decisions.
} 
Bigoni et al. (2012) find that the presence of an antitrust authority reduces the number of cartels formed in duopoly markets, but increases the cartel overcharges. Similar results about the effect of fines and detection probabilities, and their interaction with leniency on collusion in an oligopoly framework comparable to this study are reported by Chowdhury and Wandschneider (2013). Chowdhury and Wandschneider (2014) experimentally show that the negative effect of fines on collusion is significantly reduced if firms have the (costly) option to invest in avoidance activities reducing the probability of cartel detection. Experimental evidence on the effects of leniency programs is mixed. Hinloopen and Soetevent (2008) find that their existence reduces cartel formation and success by lowering the prices charged by cartels as well as their survival rates. Although supporting the negative effect of leniency programs on cartel formation, Bigoni et al. (2012) find that surviving cartels are more stable. This result is in line with the theoretical model of Motta and Polo (2003) which suggests that leniency programs can facilitate collusion by reducing the expected fine if used. Similar implication arise for whistleblower rewards in Apesteguia et al. (2007). Ambiguous effects of leniency programs are found for collusion in auctions (Hinloopen and Onderstal, 2014). Bigoni et al. (2015) find that the deterrent effect of leniency programs in cartel experiments primarily is driven by distrust induced by these programs, and not fines. This finding stresses the importance of beliefs as a source for collusion in the same spirit as collusive learning in the theoretical model in Section 2.2.

In this experiment, three firms engage in homogenous goods Bertrand competition with perfectly inelastic demand as proposed first by Dufwenberg and Gneezy (2000). Triopolies are used because previous studies find three firms are enough to prevent significant levels of collusion without communication in both Bertrand (Dufwenberg and Gneezy, 2000; Wellford, 2002) and Cournot (Huck et al., 2004) market experiments. Therefore, three-firm markets require communication for collusion and are a good choice to study PCTC because collusion as well as reciprocity are easy in markets with two firms. Empirical evidence from the field provide the same conclusions. Kwoka (1979) and Bresnahan and Reiss (1991) observe, on average, that as soon as there are three firms in the market, markets are characterized by competition and lack of coordination and collusion. Kovacic et al. (2007) study PCTC in the Vitamins industry, and find that duopoly markets continue to charge collusive prices after the detection of cartels, but not necessarily for markets with three or more firms.

We use a Bertrand oligopoly market similar to that of Gillet et al. (2011) and combine it with a variation of the communication and no communication design of Fonseca and Normann (2012). Using a predefined fixed length of periods with communication allows for a clear identification of the effect of learning and preceding cartel success on PCTC with respect to stability, persistence, and cheating. We implement a three firm homogeneous goods rather than a two firms differentiated goods market (such as in Bigoni et al., 2012), as experimental triopolies usually produce results that better reflect market outcomes in oligopoly markets in the field. In addition, this significantly reduces the complexity of the decision making process of subjects as well as the impact of subjects' learning effects on outcomes. Thus, whereas this study is more general with respect to firm numbers, Bigoni et al. (2012) is more general with 
respect to product differentiation. A comparison of a subset of results of this study with those of Bigoni et al. (2012) shows that the results are similar in both environments.

The experiment consists of four stages. In the first stage, firms are asked "Do you want to agree on prices?", i.e., whether they want to form a cartel. An agreement is only reached when all three firms in the market confirm that they want to agree on prices. If it is reached, a message is displayed that all firms agreed to set the price of 102. However, the agreement is non-binding, i.e., firms are not required to follow the price agreement. In the second stage, firms are asked to make a price decision. Each firm can charge a price integer between 90 and 102 facing costs of 90 in case it sells the good. Therefore, a firm's profit equals Price - 90 if it sells the good and $\mathbf{0}$ otherwise. It does not sell the good, earning a profit of 0 , if another firm charges a lower price. In case either two or all three firms charge the same lowest price, the profits are equally shared between them. Thus, demand is characterized by a computerized buyer that buys either 1 or 0 units from each firm depending on whether that firm set the lowest price in that round. Subsequently, we refer to the price entered by subjects as the asking price, and to the lowest price in a market as the market price. There are several Nash equilibria in this framework. In an equilibrium two firms charge 90 and the remaining firm charges any price including 90; or all firms charge 91. However, the latter equilibrium is both the payoff-dominant as well as the unique equilibrium in strategies that are not weakly dominated. In the third stage, the firms learn about each other's prices. In this stage, they also face additional treatment-specific information and choices. In the last stage, firms learn their profits from the period. Figure 1 depicts the sequence of the experiment, showing the four stages and the main information in them.

Figure 1: Sequence of the experiment

\begin{tabular}{|c|c|c|c|}
\hline Collusion decision & Price decision & Feedback & Final outcome \\
\hline $\begin{array}{l}\text { - First } 10 \text { periods } \\
\text { only } \\
\text { - Yes/No question } \\
\text { whether agreement } \\
\text { shall be attempted }\end{array}$ & $\begin{array}{l}\text { - Information } \\
\text { whether } \\
\text { cartel formed } \\
\text { - Price choice } \\
\text { required }\end{array}$ & $\begin{array}{l}\text { - Learn price } \\
\text { choices of all } \\
\text { firms } \\
\text { - (who are the } \\
\text { min price } \\
\text { firms) }\end{array}$ & $\begin{array}{l}\text { - Profits are } \\
\text { reported } \\
\text { - Learn about } \\
\text { potential } \\
\text { detection and } \\
\text { fines }\end{array}$ \\
\hline
\end{tabular}

In all treatments except for the Baseline and ExtComm treatments introduced below, the firms can communicate for the first 10 periods in the Communication phase, but communication is disallowed for the rest of the game in the No Communication phase. Subjects do not know that they are able to communicate for the first ten periods only, but are told that they may have the option to agree on prices. This uncertainty ends at the beginning of period 11 when subjects are informed that from this point onwards communication is not possible and that previous agreements cannot be discovered anymore either. This design prevents strategic behavior of subjects from affecting the transition from explicit to tacit collusion: no cheating should be triggered by the anticipation of the end of communication. An overview of the possibility to 
communicate for all treatments can be found in Table 1.

Table 1: Communication in treatments

\begin{tabular}{l|ccc}
\hline Treatments & $\begin{array}{c}\text { No Communication } \\
\text { phase }\end{array}$ & $\begin{array}{c}\text { Communication } \\
\text { phase }\end{array}$ & $\begin{array}{c}\text { No Communication } \\
\text { phase }\end{array}$ \\
\hline Baseline & - & $\times$ & $\times$ \\
Comm & - & $\checkmark$ & $\times$ \\
ExtComm & $\times$ & $\checkmark$ & $\times$ \\
Fine & - & $\checkmark$ & $\times$ \\
Leniency & - & $\checkmark$ & $\times$ \\
MRemoval & - & $\checkmark$ & $\times$ \\
\hline Periods & -9 to 0 & 1 to 10 & 11 to 20 \\
\hline
\end{tabular}

Notes: A $\checkmark$ indicates that communication is possible in the time periods, and in periods denoted with $\times$ firms cannot communicate. The dash (-) denotes that in all but the ExtComm treatment directly start with communication in the Communication phase.

Baseline: In Baseline, firms cannot communicate at any point and each round starts directly with the price decision. It serves as the benchmark for tacit collusion that can be obtained without communication. Any difference in price levels between the Baseline treatment and other treatments in which firms can communicate that is higher represent gains from communication.

Comm: In the Comm treatmemt, firms can agree on prices as described above for 10 periods during the Communication phase, but not afterwards in the No Communication phase. Communication facilitates collusion by eliminating uncertainty about past and present action and by providing information about the firm's discount factors (Vermeulen et al., 2013; Mouraviev, 2006). This treatment is the equivalent of the relevant treatment in Fonseca and Normann (2012). The marginal effect of variations in the market characteristics on the gains from collusion can be examined by comparing the other treatments with communication to this treatment.

ExtComm: The ExtComm treatment is introduced to test whether experience of competition before cartel formation affects the incidence of tacit collusion after the end of communication. In this treatment, the Communication and No Communication stages of the Comm treatment are supplemented by an additional 10 initial periods of no communication. Subsequently, we do not analyze these initial 10 periods but focus on the other 20 periods which are comparable to the other treatments. Subjects could learn about the Nash equilibrium in the initial competitive periods and revert to the Nash equilibrium more quickly after the breakdown of collusion. Further, they might have a better understanding of the benefits of communication in this treatment because of preceding exposure to low profits during competition.

Fine: The Fine treatment allows for the analysis of the effect of an antitrust authority on the gains from communication. In Fine firms face an exogenous detection probability of $16 \%$ by an antitrust authority if they agree to fix a price in the Communication phase. This detection probability is in the range of the estimate between 13\%-17\% provided by Bryant and Eckard (1991). Detection is possible either in the period in which the agreement is formed or in subsequent periods. Detected firms have to pay a fine of 5 experimental points. An agreement 
can only be discovered once such that new fines are not possible unless another agreement is formed in a subsequent period. ${ }^{11}$

$\square$ Leniency: The Leniency treatment is an extension of the Fine treatment. Firms can submit a leniency application after learning about each others' prices if they formed a cartel in the same period or a previous cartel so far remained undetected. A leniency application can only be submitted in the Communication phase and if a cartel is formed in the same round or if a previous cartel agreement has not been discovered yet. Fine reductions for leniency applicants are similar to Hamaguchi et al. (2009) and Bigoni et al. (2012). In case only one firm submits a leniency application, it does not receive a fine but the other two firms have to pay the full fine of 5. If two firms submit a leniency application, both whistleblowers only have to pay half of the fine and the third firm has to pay the full fine. In case all three firms use the leniency scheme, they have to pay $1 / 3$ of the fine. The fine is chosen such that the incentive compatibility constraint between the Fine and Leniency treatments are roughly identical (given collusion on the price of 102, they are approximately 0.66 and 0.68 , respectively, if only one firm deviates to price 101 and is the only one to submit a leniency application in case of the Leniency treatment). A cartel is always discovered if at least one leniency application is submitted, but firms are not informed whether detection was triggered by exogenous detection or leniency applications.

MRemoval: The MRemoval treatment introduces a mechanism aimed at disrupting PCTC by targeting the channels through which it works as identified in Section 2. In this treatment, firms can freely communicate in the absence of a competition authority for 10 periods as in the Comm treatment. The only difference between MRemoval and Comm is that in MRemoval subjects are informed that they will be rematched with two other randomly chosen subjects at some point in the game. From a supergame perspective, this should yield lower rates of cooperation by reducing the horizon for cooperation. In line with cartels in the field, the point of time in which managers are rematched is not revealed to the subjects. This potentially creates uncertainty due to different expectations of the duration of cooperation in the supergame further destabilizing collusion. Subjects are informed that they will interact with the same two participants until the rematching and that they will be informed about this rematching prior to this change. The rematching is carried out prior to period 11 with the end of communication to ensure that firms cannot learn about the new firms and managers that they are sharing a market with using communication. After the rematching, subjects cannot observe the history of the industry. This is a deliberate choice to prevent focal points to drive tacit collusion. ${ }^{12}$ As such, any change in collusion observed in this treatment in period 11 compared to the Comm and ExtComm treatments comes from the disruption of the effects of learning.

\footnotetext{
${ }^{11}$ In line with the related experimental papers, the detection probability or fine do not depend on the number of agreements, that is they remain the same no matter whether the detected firms agreed once or several times before discovery. The effect of endogenous fines and detection probabilities on collusion and price choice is studied in Crede and Lu (2015).

${ }^{12}$ One might argue that subjects may continue to charge previous collusive prices in a new market, and that this is caused by behavioral inertia rather than strategic choice. However, this is not the case. We do not observe a single subject in MRemoval charging a price of 102 both in period 10 and period 11.
} 
The mechanism in MRemoval features effects similar to (criminal) sanctions against managers involved in cartels with respect to PCTC. Rematching of subjects into new groups emulates the removal of convicted cartel managers from their positions. However, a major difference is unlike in the field where the removal of cartel managers due to criminal sanctions hinders them to take up similar positions in any industry, in our experiment subjects continue to participate in other markets. This allows us to test whether prohibiting managers to take up similar positions in other industries prevents attempts of collusion in these markets. Sanctions against cartel managers can come in the form of monetary fines, imprisonment, or debarment, i.e., disqualification from taking up managing positions in the same or similar industries after conviction. Henceforth, we focus on imprisonment and debarment, i.e., sanctions that require convicted managers to either temporarily or permanently give up their previous position. The enforcement effects of sanctions against managers can be separated into direct and indirect effects. Define the effects on the individual, such as fines against the manager or a prison sentence, as the direct enforcement effects of sanctions of cartel managers. A multitude of differences in the sanctions across competition regimes as well as ambiguous follow-up effects such as gains or losses of reputation inducing both further monetary and non-monetary effects on the affected managers renders it difficult to model these sanctions in the lab. ${ }^{13}$ As such, we refrain from modelling direct enforcement effects and focus on the indirect enforcement effects that denote the effects on the firm which employed the manager. The MRemoval treatment captures the indirect enforcement effects relevant to PCTC: the rematching mechanism eliminates previous learning effects, removes the collusive history between firms in a market, and creates uncertainty both before and after the rematching. A similar focus on indirect enforcement effects can be found in Bigoni et al. (2015), in which leniency is shown to be detrimental to collusion in the absence of monetary fines by eroding trust between cartel members. The overall effect of sanctions of managers on collusion is therefore likely to be higher due to the direct enforcement effects.

\subsection{Hypotheses}

Based on the existing literature and insights derived from the theoretical model, several hypotheses with respect to PCTC can be derived. Note that hypotheses H1 and H2 below will refer to the Comm, ExtComm, Fine, and Leniency treatments, but not the MRemoval treatment that receives its own hypotheses H3 and H4. The empirical and experimental studies discussed above indicate that PCTC appears to exist in market environments both with and without an antitrust authority. Generalizing the findings of these studies from various situations and regimes allows us to construct the first hypothesis: provided that tacit collusion is triggered by learning in cartels or collusive price hysteresis as defined in Section 2, PCTC should occur in the experiment irrespective of variations in the design of the antitrust authority (with the exception of the MRemoval treatment).

\footnotetext{
${ }^{13} \mathrm{~A}$ recent overview with respect to differences of sanctions against cartel managers across countries can be found in Ginsburg and Wright (2010). The effect of criminal sanctions on reputational is not necessary negative. For example, managers in the Auto Parts Cartel were re-employed after serving their jail sentences and received company support during imprisonment (Greimel, 2014).
} 
H1 (Existence): PCTC is not caused by specific competition laws.

Although antitrust laws are not a necessary condition for PCTC, they can still affect it such as in Harrington (2004). If Hypothesis 1 holds, the magnitude of supercompetitive prices generated by PCTC might be linked to preceding cartel success. This relationship has two dimensions. First, firms could stick to the last cartel price after communication has ended. Therefore, economic environments favorable to cartel formation, on average, might have a higher incidence of tacit collusion. Second, preceding cartel stability might also play a role for the incidence of tacit collusion. As predicted in the theoretical model, cartel stability contributes to PCTC through its effects on firm's expectations about the likelihood of cheating by others. Therefore, we propose the following hypothesis with respect to the determinants of PCTC:

H2 (Determinants): The magnitude of overcharges reached with tacit collusion after cartels is determined by learning in cartels and collusive price hysteresis. Previously more successful cartels realize higher post-cartel supercompetitive profits.

The consequences of Hypothesis 2 with respect to cartel damage estimations are discussed in Section 4.3. The next two hypotheses relate to the removal of cartel managers as a policy tool to reduce or prevent PCTC: H3 is concerned with the market outcome after the end of the cartel, and $\mathrm{H} 4$ focuses on the effects of such programs on the cartel outcome. As stated before, hypotheses $\mathrm{H} 1$ and $\mathrm{H} 2$ do not apply to the MRemoval treatment. Removal of managers from the market might prevent PCTC as proposed in the theoretical model: if PCTC indeed benefits from learning through preceding communication, we should not observe significant levels of tacit collusion in the MRemoval treatment. The reason for this is any previous learning is made redundant due to the rematching of managers.

H3 (Prevention): There is no PCTC in the MRemoval treatment.

Note that the rematching might destabilize collusion in the cartel-periods already as it reduces the expected benefits of cooperation. Strategic cooperation based on reputation building and learning becomes less attractive. Anticipating the instability induced by the removal of key personnel in the cartel after detection should therefore increase cheating.

H4 (Reduction): Potential removal of managers destabilizes collusion and increases the incidence of cheating.

\section{Results}

\subsection{Transition from explicit to tacit collusion}

As a first step, we test whether the existence of PCTC is robust to differences in the competition regimes. In the analysis of firm behavior, we shall distinguish between the asking and market prices; both are important outcome variables. The market price serves the whole market in a homogeneous goods Bertrand game without capacity constraints and is the relevant market 
outcome from a welfare perspective. The asking price captures additional information related to firm-level activity such as price signalling or failed attempts to collude. This is in particular of importance in periods in which communication is not possible: by deviating from the Nash equilibrium and setting a price of 102, firms can signal their intentions to establish collusion.

Figure 2: Average treatment market prices across time

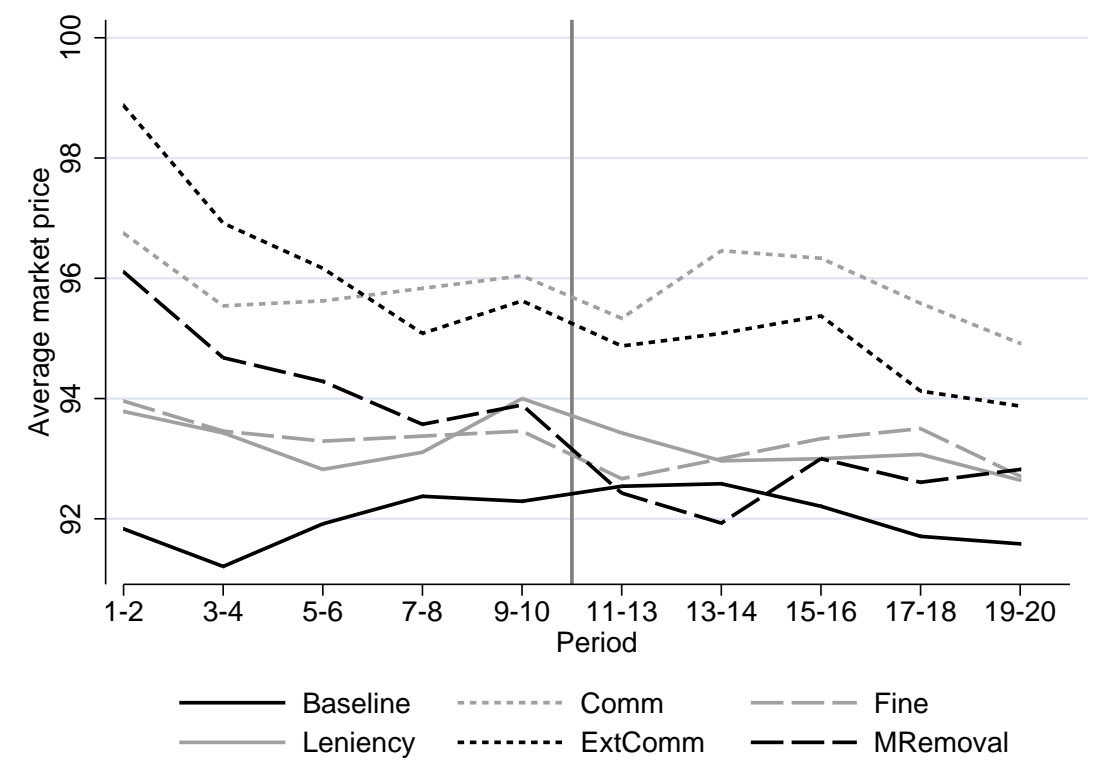

A first impression of the results can be obtained by looking at the development of market prices over time in Figure 2. For the ExtComm treatment, the line starts with the first period of communication. The vertical grey line marks the transition from the Communication phase to the No Communication phase. The Baseline treatment shows that firms, on average, are able to establish tacit collusion to a limited extent, as its average market price is above the payoff dominant Nash equilibrium price of 91. Comparing all other treatments to this benchmark shows that communication allows firms to achieve higher prices both during periods with communication by forming cartels as well as afterwards by resorting to tacit collusion. The treatments differ in the average market price both in the Communication and No Communication phases. However, the order of treatments with respect to the average price level remains largely the same. This provides a first clue that PCTC might be determined by the market outcomes in the Communication phase. In addition, there appears to be a significant level of price hysteresis and little initial change of market outcomes after the end of communication despite the sudden loss of the ability to communicate. Results of the MRemoval treatment suggest that the announced rematching of managers destabilizes collusion. Further, removal of convicted managers after the end of communication might effectively prevent PCTC.

Table 2 contains both asking and market prices separated by treatment in Communication and No Communication phases. For the Baseline treatment, for convenience we include the first and last ten periods into the Communication and No Communication columns, respectively. As the market prices are the market-clearing prices they are at least as low as asking prices in all treatments. Both in the Communication and No Communication phases the Comm and 
Table 2: Asking and market prices by Communication possibility

\begin{tabular}{lcccccccc}
\hline & \multicolumn{3}{c}{ Communication periods } & \multicolumn{3}{c}{ No Communication periods } \\
\hline & \multicolumn{3}{c}{ Asking prices } & \multicolumn{2}{c}{ Market prices } & \multicolumn{2}{c}{ Asking prices } & \multicolumn{2}{c}{ Market prices } \\
& Mean & Std. dev. & Mean & Std. dev. & \multicolumn{2}{c}{ Mean } & Std. dev. Mean & Std. dev. \\
Baseline & 93.328 & 3.324 & 91.925 & 2.338 & 93.436 & 3.600 & 92.125 & 2.410 \\
Comm & 97.744 & 4.816 & 95.958 & 5.004 & 96.925 & 4.968 & 95.725 & 5.042 \\
Fine & 94.978 & 4.019 & 93.508 & 3.498 & 94.206 & 4.229 & 93.042 & 3.487 \\
Leniency & 95.276 & 4.784 & 93.429 & 4.125 & 94.595 & 4.699 & 93.021 & 3.888 \\
ExtComm & 98.078 & 4.769 & 96.533 & 5.002 & 95.817 & 4.979 & 94.667 & 4.731 \\
MRemoval & 96.874 & 4.730 & 94.507 & 4.365 & 95.238 & 4.725 & 92.557 & 3.232 \\
\hline
\end{tabular}

ExtComm treatments feature the highest asking and market prices, and the Baseline treatment the lowest. On average, the Leniency treatment features higher asking and market prices than the Fine treatment. Whereas market prices in the MRemoval treatment are close to those of the Comm and ExtComm treatments, they are subject to a significant decline in the No Communication phase and very close to the Baseline treatment.

Table 3: Market prices by phase - MWU test p-value matrix

\begin{tabular}{lccccc}
\hline & Comm & Fines & Leniency & ExtComm & MRemoval \\
\hline Communication phase & & & & & \\
Baseline & 0.000 & 0.000 & 0.040 & 0.000 & 0.000 \\
Comm & & 0.006 & 0.000 & 0.563 & 0.027 \\
Fine & & & 0.034 & 0.000 & 0.425 \\
Leniency & & & 0.000 & 0.025 \\
ExtComm & & & & 0.002 \\
\hline No communication phase & 0.000 & 0.024 & 0.373 & 0.000 & 0.685 \\
Baseline & & 0.001 & 0.000 & 0.131 & 0.000 \\
Comm & & & 0.222 & 0.069 & 0.073 \\
Fine & & & & 0.008 & 0.488 \\
Leniency & & & & & 0.001 \\
ExtComm & & & & \\
\hline
\end{tabular}

Notes: Periods 1-10 are used for the Baseline treatment in the comparison of market prices in the No Communication phase.

Table 3 contains pairwise Mann Whitney U (MWU) tests of market prices between treatments separated by the Communication and No Communication phases to assess whether price differences are significant. ${ }^{14}$ In the absence of a robust transition from explicit to tacit collusion, the market prices between the Baseline treatment and the Communication treatments should roughly be the same. Combining results in Tables 2 and 3 confirms the observation that the order of treatments with respect to market prices is stable throughout the experiment due to a robust transition from explicit to tacit collusion. The order of treatments with respect to collusion is the same for both Communication and No Communication phases, with the Comm and ExtComm treatments being the highest, followed by the Fine and Leniency treatments,

\footnotetext{
${ }^{14}$ Equivalent tests for the asking prices can be found in Table 6 in Appendix B.
} 
and Baseline being the lowest. This suggests that PCTC is indeed linked to preceding cartel success. The key result (as can be seen in the first row of the No Communication phase in Table 3 ) is that apart from the MRemoval and Leniency treatments, communication enables firms to achieve significantly higher prices than possible with pure tacit collusion (i.e., in Baseline) in the No Communication phase. A lack of significant differences between the Baseline and Leniency treatments here does not indicate the absence of PCTC in the Leniency treatment, as can be seen in Figure 4 below. As only 2 out of 12 markets form cartels in the Leniency treatment, the influence of these markets on average market prices is loo low to detect PCTC on an aggregate level. Thus, we can confirm Hypothesis 1.

Result 1: PCTC occurs irrespective of differences of competition laws.

Market prices between the MRemoval and Baseline treatments do not differ in the No Communication phase. This suggests that the payoffs from communication on market prices cease to exist in the MRemoval treatment after the rematching of managers confirming Hypothesis $3 .{ }^{15}$

Result 2: The removal of cartel managers from the market prevents PCTC.

Another result arises from Tables 2 and 3 with respect to the effect of the manager removal mechanism on cartels. There is strong evidence that market prices in the Communication phase in the MRemoval treatment are significantly lower than in the Communication treatment. As the two treatments are identical aside from the announcement of future rematching of the groups in the MRemoval treatment, we can attribute the lower market prices in the MRemoval treatment to a negative effect of the potential rematching on collusion. To determine how rematching affects cartels, we compare collusion and cheating in the Communication phase between treatments.

Figure 3: Incidence of cartelization and cheating in the communication stage

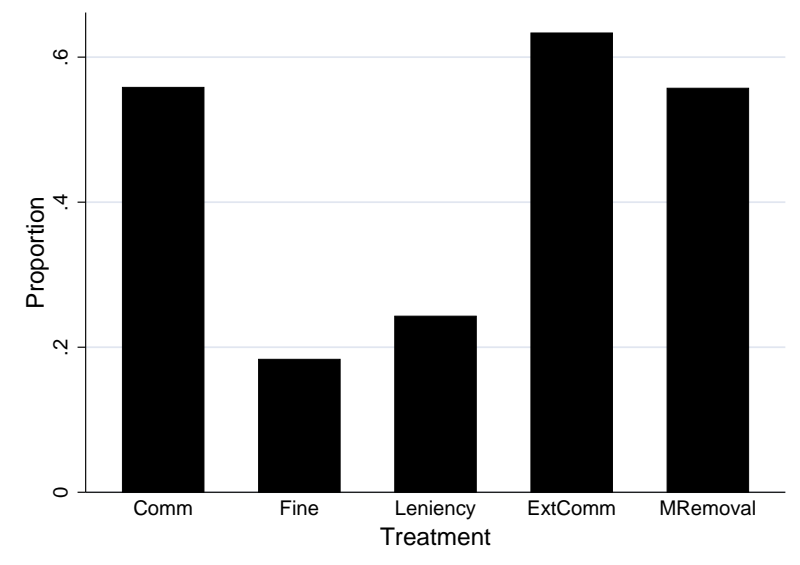

(a) Proportion of firms colluding

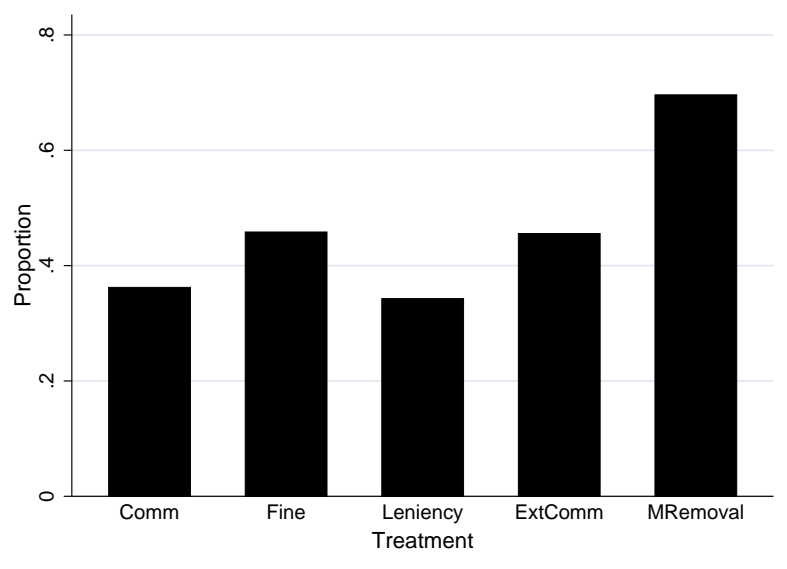

(b) Proportion of firms cheating

\footnotetext{
${ }^{15}$ As will be argued below, the reason market prices seem to recover during the end of the experiment in the MRemoval treatment are successful attempts of cartelists to establish collusion in new markets. Proper removal of cartel managers should result in the replacement of convicted managers with new ones that have not been involved in cartels before, and therefore, lower market prices.
} 
Figures $3 \mathrm{a}$ and $3 \mathrm{~b}$ depict differences in the proportion of markets with price agreements and cheating conditional on the existence of an agreement in the Communication phase. Cheating here refers to a firm's decision to charge a price below 102 when an agreement was reached in either the same period or a previous periods' agreement has not been undercut by any of the firms yet. Pairwise Fisher's exact tests (Table 7 in Appendix B) indicate that the proportion of cartel formation is significantly different between all treatments except for the proportions between the Fine and Leniency as well as between the Comm and ExtComm treatments, and that MRemoval is not different from the Comm and ExtComm treatments. A matrix containing p-values from Fisher's exact tests of differences in the proportion of cheating in cartelized markets between treatments can be found in Appendix B (Table 8). The proportion of cheating is not different between any treatments except for MRemoval, which features significantly higher levels of cheating than all other treatments. Thus, the possible rematching of managers does not reduce attempts to collude in experiments but significantly increases the incidence of cheating. This destabilizing effect is very pronounced with the proportion of firms cheating shooting up from $36.23 \%$ in the Comm treatment to $69.62 \%$ in the MRemoval treatment, confirming Hypothesis 4.

Result 3: A potential removal of managers negatively affects explicit collusion. The source of this effect is a reduction of cartel stability triggered by anticipation of the future removal of managers from other firms in the market.

However, this finding has a caveat. Unlike in the field where the removal of managers from the market is directly linked to cartel detection, no such link exists in the experiment, as the end of communication was not specified to subjects. Compared to the treatment, the "risk" of removal of managers in other firms engaged in a cartel might (or might not) be regarded as smaller in the field, as it is not an unspecified risk of an event that occurs with $100 \%$ certainty but is limited to cartel detection. Nevertheless, the same qualitative predictions can be expected for cartels in the field. Also, notice that there is no personal punishment existent in the experiment unlike in the field, in which debarment or even imprisonment represent severe (monetary) sanctions. These criminal sanctions further strengthen the effect of criminal sanctions on market outcomes. The above results are visualized in Figure 4 by separating market prices between markets with and without at least one cartel period. The vertical gray line marks the last period of communication, and market prices are averaged over two periods. Firms successfully forming a cartel are able to charge higher prices throughout the experiment. Whereas in line with predictions of the theoretical model prices appear to diminish over time for previously successfully colluding firms, no such period effects are evident for the other firms. Notice the sudden decline in market prices in the MRemoval treatment, which displays the immediate breakdown of collusion due to the rematching. 
Figure 4: Market prices by preceding cartel success

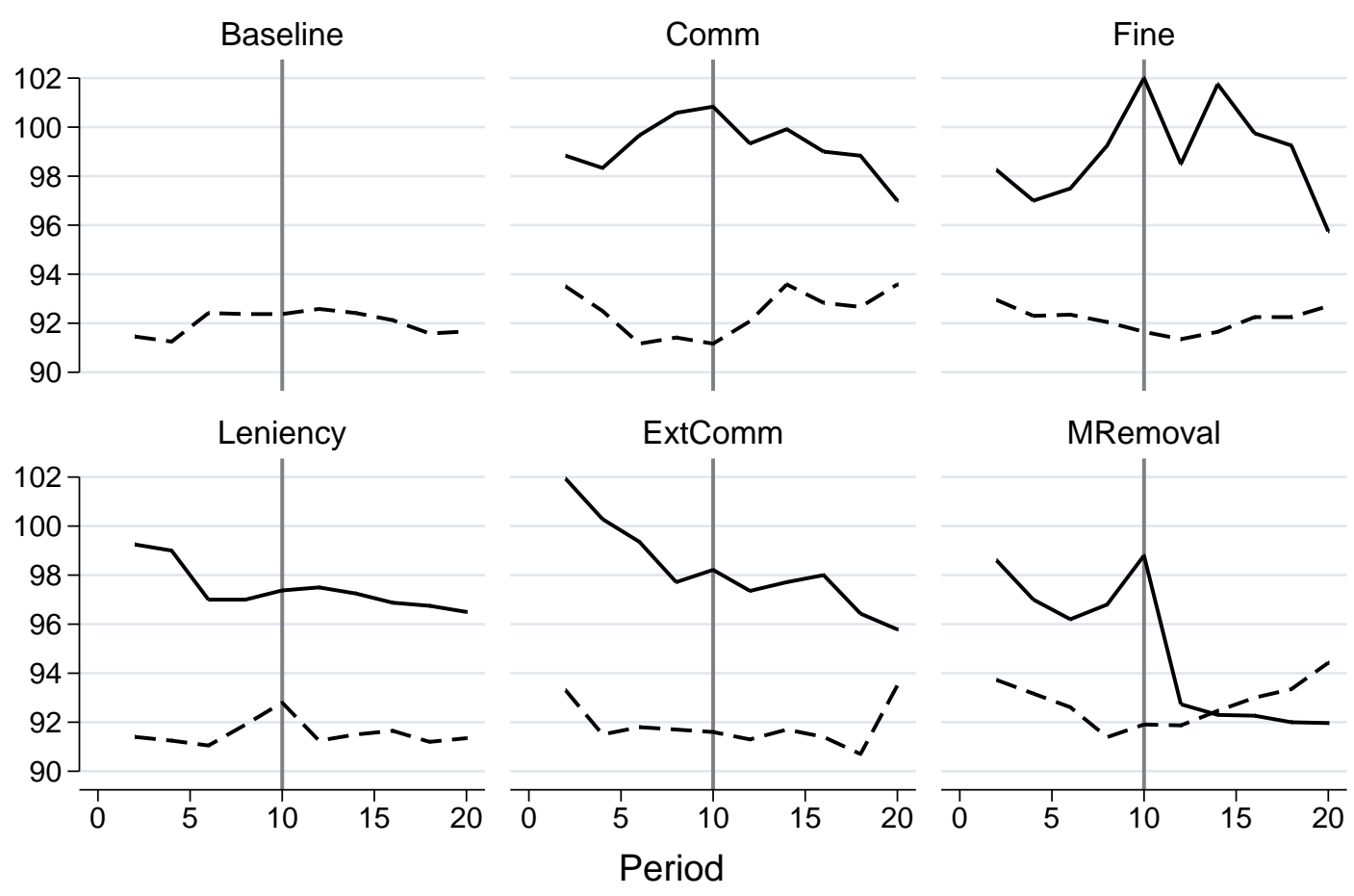

Successful cartels - - - - No Cartels

\subsection{Sources of post-cartel tacit collusion}

Next we turn to the determinants of PCTC and regress asking and market prices in the No Communication phase on other important market outcomes in Table 4. A specification is chosen that allows to capture the different sources of PCTC and distinguish them from any tacit collusion that is established by price signalling only. For this purpose, we include variables aimed at capturing the sources of PCTC defined in Section 2.1 and introduce indicator variables for all treatments with communication using the Baseline treatment as the baseline. Therefore, the treatment dummies control for treatment specific effects on PCTC that are not captured in any of the other included regressors.

The regressions are calculated based on the Correlated Random Effects (CRE) model (Mundlak, 1978; Wooldridge, 2010). ${ }^{16}$ For all estimations, cluster and autocorrelation-robust standard errors are used. Results with respect to asking and market prices are presented for all treatments excluding MRemoval in columns I and III, respectively. We analyze asking and market prices in the MRemoval treatment separately due to the potentially very different nature of tacit collusion

\footnotetext{
${ }^{16} \mathrm{CRE}$ models combine the fixed effects (FE) and random effects (RE) models in a unified framework that allow to estimate level 2 variables (e.g., variables that vary by subject but not over time) despite controlling for unobserved heterogeneity with fixed effects. In addition, they are less restrictive with respect to unobserved heterogeneity than $\mathrm{RE}$ models and do not require the random effects to be uncorrelated with the explanatory variables. Regression results based on the "classical" RE model can be found in Table 9 in Appendix B. The results are robust to the choice of the estimator. There are only differences to various degrees in the magnitude of coefficients, which might be attributed to the lack of control for unobserved heterogeneity in the RE model, which do not affect the qualitative findings.
} 
in this treatment in columns II and IV. Lag price represents the corresponding previous period's own asking and market price in columns I-II and III-IV, respectively. Lag other players' prices contains the average of the other two firms' asking prices in a player's market in the previous period and is included in the asking price regression only. We use two different variables to measure the effect of preceding collusion on pricing. Lag collusion is an indicator variable that takes the value 1 if all three firms charged the collusive price of 102 in the previous period. This variable measures collusive price hysteresis. No. of successful cartel periods contains the market's number of periods of successful cartelization in the preceding Communication phase, i.e., all firms agreed to fix prices and did not cheat. ${ }^{17}$ For all treatments except for the MRemoval treatment, it captures the effect of preceding cartel success on PCTC. It corresponds to the effect of learning in cartels on tacit collusion after cartels in the theoretical model. For the MRemoval treatment the interpretation is different. The preceding analysis has shown that criminal sanctions have a strong and immediate negative impact on PCTC. However, unlike in the field where managers replacing those convicted in cartels most likely have no experience in collusion, our re-matching procedure allows us to observe how subjects with such a history behave in a new market environment. Therefore, the coefficient in Column II shows whether a subject's intention to establish collusion with price signalling is driven by preceding experience of collusion. In Column IV, the variable captures the average collusive experience in the new market, and shows how successful price signalling triggered by former collusion contributes to market prices. The variable Period measures period effects. We also include an interaction of the period with the measure of cartel success, Period $\times$ No. of successful cartel periods. Comm, Fine, Leniency, and ExtComm are treatment indicators, with the Baseline treatment being the baseline category for the regressions in Columns I and III. To prevent potential transition effects resulting from the switch from periods with communication to those without it, the regressions are based on Periods 12-20 only. This ensures that prices only from periods without communication (ignoring the periods -9 to 0 in ExtComm) are included in the regressions.

Unlike the RE estimator, the CRE model separates between and within variation in multilevel data. The panel variable in asking prices is subjects and in market prices it is markets. Variables without a $\varnothing$ symbol control for within-group effects. A group mean-centered variation is included as well: the corresponding coefficients with a $\varnothing$ symbol belongs to the effect of the cluster-specific mean of the variable and captures the between-groups effect. This coefficient is hard to interpret because it captures both the between effects in the sample as well as the captured unobserved heterogeneity (the fixed effect). However, significance of the coefficient of this variable indicates evidence of between variation with respect to the variable under consideration. No such decomposition is necessary for the treatment dummies as well as the constant, as they do not vary over time or between the groups.

\footnotetext{
${ }^{17}$ In the MRemoval treatment, the three players come from markets with a different history of collusion. Therefore, we use the average value of the variable across the three markets that the subjects come from in the treatment. This allows us to control for the effect of the average level preceding experience of successful collusion of subjects on PCTC after rematching. Such an approach does not impose strong assumptions with respect to the rematching procedure.
} 
Table 4: Prices in the No Communication periods

\begin{tabular}{|c|c|c|c|c|}
\hline \multirow[b]{3}{*}{ Baseline: Baseline } & I & II & & IV \\
\hline & \multicolumn{2}{|c|}{ Asking price } & \multicolumn{2}{|c|}{ Market price } \\
\hline & $\begin{array}{l}\text { Coeff. } \\
\text { (Std.E.) }\end{array}$ & $\begin{array}{l}\text { Coeff. } \\
\text { (Std.E.) }\end{array}$ & $\begin{array}{c}\text { Coeff. } \\
\text { (Std.E.) }\end{array}$ & $\begin{array}{l}\text { Coeff. } \\
\text { (Std.E.) }\end{array}$ \\
\hline \multirow[t]{2}{*}{ Lag price } & $0.270^{\dagger}$ & $0.309^{\dagger}$ & $0.522^{\dagger}$ & $0.210^{* * *}$ \\
\hline & $(0.056)$ & $(0.045)$ & $(0.066)$ & $(0.075)$ \\
\hline \multirow[t]{2}{*}{ Lag other players' prices } & $0.114^{* *}$ & 0.104 & - & - \\
\hline & $(0.058)$ & $(0.094)$ & & \\
\hline \multirow[t]{2}{*}{ Lag collusion } & $1.513^{\dagger}$ & $2.179^{* * *}$ & $2.071^{* * *}$ & $6.005^{\dagger}$ \\
\hline & $(0.443)$ & $(0.713)$ & $(0.753)$ & $(0.883)$ \\
\hline \multirow[t]{2}{*}{ No. of successful cartel periods } & $0.217^{* *}$ & $0.961^{* * *}$ & $0.313^{* * *}$ & 0.400 \\
\hline & $(0.107)$ & $(0.325)$ & $(0.117)$ & $(0.611)$ \\
\hline \multirow[t]{2}{*}{ Period } & 0.018 & 0.039 & 0.015 & 0.021 \\
\hline & $(0.044)$ & $(0.095)$ & $(0.031)$ & $(0.084)$ \\
\hline \multirow{2}{*}{$\begin{array}{l}\text { Period } \times \text { No. of } \\
\text { successful cartel periods }\end{array}$} & $-0.016^{* *}$ & $-0.062^{* * *}$ & $-0.023^{\dagger}$ & -0.025 \\
\hline & $(0.007)$ & $(0.020)$ & $(0.007)$ & $(0.039)$ \\
\hline \multirow[t]{2}{*}{ Comm } & 0.007 & - & -0.041 & - \\
\hline & $(0.179)$ & & $(0.230)$ & \\
\hline \multirow[t]{2}{*}{ Fine } & 0.099 & - & -0.022 & - \\
\hline & $(0.125)$ & & $(0.163)$ & \\
\hline \multirow[t]{2}{*}{ Leniency } & -0.052 & - & -0.077 & - \\
\hline & $(0.109)$ & & $(0.152)$ & \\
\hline \multirow[t]{2}{*}{ ExtComm } & -0.133 & - & -0.089 & - \\
\hline & $(0.150)$ & & $(0.124)$ & \\
\hline \multirow[t]{2}{*}{$\varnothing$ Lag price } & $0.633^{\dagger}$ & $0.651^{\dagger}$ & $0.499^{\dagger}$ & $0.646^{\dagger}$ \\
\hline & $(0.054)$ & $(0.074)$ & $(0.047)$ & $(0.086)$ \\
\hline \multirow[t]{2}{*}{$\varnothing$ Lag collusion } & $-1.449^{* *}$ & -0.367 & $-2.107^{*}$ & $-1.936^{*}$ \\
\hline & $(0.684)$ & $(0.890)$ & $(1.180)$ & $(1.048)$ \\
\hline \multirow[t]{2}{*}{$\varnothing$ Lag other players' prices } & 0.014 & -0.081 & - & - \\
\hline & $(0.061)$ & $(0.113)$ & & \\
\hline \multirow[t]{2}{*}{ Constant } & -3.342 & 0.829 & -2.105 & $12.801^{* * *}$ \\
\hline & $(2.879)$ & $(3.642)$ & $(5.262)$ & $(4.947)$ \\
\hline$R^{2}$ overall & 0.753 & 0.499 & 0.878 & 0.635 \\
\hline$R^{2}$ between & 0.987 & 0.965 & 0.990 & 0.992 \\
\hline$R^{2}$ within & 0.131 & 0.185 & 0.407 & 0.399 \\
\hline Observations & 1,674 & 378 & 558 & 126 \\
\hline
\end{tabular}

Notes: $* 10 \%$ level, $* * 5 \%$ level, $* * * 1 \%$ level, $\dagger 0.1 \%$ level. - Cluster and autocorrelation-robust standard errors in parentheses. - Columns I and III contain observations for all treatments except for MRemoval, and Columns I and IV are based on MRemoval treatment observations only. All estimations are based on CRE regressions. 
Column I provides strong evidence that a firm's prices positively depends on its own past prices as well as on those of the other firms in the market. As expected, collusion in the preceding period has a strong positive effect on price choices. This suggests that PCTC is indeed partly caused by collusive price hysteresis. The significance and high magnitude of the positive but over time diminishing effect of preceding cartel success on the asking prices provides evidence for the effect of learning in cartels on PCTC. The coefficient for previous cartel success suggests that, on average, in market with 10 periods of collusion in the communication period firms submit asking prices that are, on average, 9.61 experimental points higher. Given that the overcharge difference between the payoff-dominant Nash and the fully collusive price is 11 experimental points, this effect is very pronounced.

The lack of significance of the treatment dummies provides support for the intuition that treatment differences with respect to tacit collusion arise from differences in the formation and stability of cartels in the Communication phase. In line with the previous analysis, this suggests that other than through their effect on cartel success, communication between firms in preceding periods does not affect prices. Further, the experimental setup with respect to relying on a Communication phase-No Communication phase setup is robust to learning effects as suggested by the insignificant coefficient for the ExtComm treatment. Turning to the market prices in Column III, the findings are robust with respect to the outcome variable with almost the same qualitative findings arising in the analysis of market prices. Therefore, it can be concluded that preceding cartel success fosters PCTC through two distinct channels: on the one hand, markets with former cartels inherit a supercompetitive price that only slowly erodes back towards competitive levels due to collusive price hysteresis. On the other hand, learning about other players' types contributes to the existence and stability of tacit collusion. Therefore, we find evidence for the determinants of PCTC confirming Hypothesis 2. This result has important consequences for the estimation of cartel damage overcharges, which will be discussed in detail in Section 4.3.

Result 4: PCTC is determined by both collusive price hysteresis and learning.

Whereas no period effects can be observed for markets without preceding communication, we find evidence of declining payoffs of preceding communication for former cartels. As Period $\times$ No. of successful cartel periods is an interaction effect, the negative coefficient suggests that this observed decline increases with preceding cartel success. Nevertheless, comparing the magnitude of the coefficient with that of No. of successful cartel periods clearly shows that overall the effect of preceding cartel success in the tacit collusion phase overall is strongly positive. This finding is in line with results of Fonseca and Normann (2012), but can only be observed for previously successfully cartelized markets.

Turning to the MRemoval treatment in Columns II and IV, subjects previously successfully colluding are more active in trying to establishing tacit collusion using price signalling as can be seen by the positive effect of preceding cartel success on asking prices in Column II. However, as the corresponding coefficient for market prices in Column IV is insignificant, these attempts 
to establish collusion in other markets are not successful. The large and positive coefficient of Lag collusion suggest that collusion is more stable after rematching, possibly because subjects are aware that re-establishment of collusion after cheating is harder to achieve without the possibility to communicate. However, as collusion on price 102 only arises in roughly $6 \%$ of the observations in the No Communication phase in the MRemoval treatment, the magnitude of the coefficient might be overstated due to the lack of observations. Note that unlike in the experiment, a properly designed debarment in the field should prevent convicted managers to take up similar managing positions in which they could try to form a cartel in the new industry. The results suggest that absent direct enforcement effects subjects try to establish collusion in new markets, but that without renewed communication these attempts are not successful. As such, when there is reason to believe that managers do not engage in explicit communication in a new position in another industry after being removed from their position in the cartel market, it might not be necessary to impose strict debarment from any managerial position in any industry: removal from the previously cartelized industry should suffice.

\subsection{Implications for cartel overcharge estimations}

The above analysis has important implications for the literature on cartel overcharge estimation. Among the different methods used to estimate cartel overcharges are before/after comparisons of prices, which are commonly used due to their simplicity and low requirements towards data (Davis and Garcés, 2009). In this approach, periods before and/or after the cartel serve as the counterfactual of a competitive industry, and differences of the price between the cartel periods and the counterfactual periods represent the cartel overcharge. PCTC leads to an increase in post-cartel benchmark prices, which undermines their validity as a competitive benchmark. This yields smaller overcharge estimates than there would have been given a valid benchmark price, which introduces the downward bias in the estimates. Given Result 4, overcharge estimates of markets previously colluding, on average, should be biased downwards.

H5 (Consequence): On average, cartel overcharges for previously colluding firms will be underestimated.

Using the before/after approach, the damages of all cartels formed in the experiment can be estimated to illustrate the issue. Three different approaches are presented. Let Pre-Cartel denote overcharge estimates that compare the price during periods of cartelization to a price benchmark that is based on prices before the cartel. Post-Cartel estimates based on post-cartel prices serving as benchmark prices, and Whole sample uses both prices before and after a cartel for the competitive counterfactual. As we have pre-communication observations only for the Baseline and ExtComm treatments, we use the average market price of the ExtComm treatment observations from periods -9 to 0 as the benchmark for all treatments. ${ }^{18}$ To calculate

\footnotetext{
${ }^{18} \mathrm{~A}$ MWU test of the market price in the periods 1-10 in the Baseline case and the periods -9 to 0 in the ExtComm treatment shows that the market prices are significantly higher in the ExtComm treatment at a $1 \%$ significance level (mean values of 91.925 and 93.475 , respectively). Therefore, the anticipated ability to communicate yields significantly higher market prices despite the lack of actual communication. As such, the
} 
the overcharges, a reasonable assessment has to be made which periods should be regarded as cartel periods. In the Comm, ExtComm, and MRemoval treatments, we include only those periods in which firms communicate and reach a price-fixing agreement. Alternatively, periods without price agreements that lie between periods with price agreements could be included into the cartel price as well. Whether exclusion of periods with potential tacit collusion between periods with price agreements in these treatments increases or decreases the overcharge estimate depends on the market outcome in these periods. If firms collude tacitly between periods with price agreements, the true damage would be higher, and it would be lower, if in these periods the firms engage in fierce competition. Fine and Leniency feature periods in which either a cartel forms or a previous cartel is undetected in the Communication stage. These differences in the composition of cartel periods reflect underlying differences in incentives for cartel formation and pricing. Given that detection is possible in the Fine and Leniency treatment even when no cartel forms in a current period but there is an existing cartel, firm behavior might be affected significantly by the presence of an antitrust authority.

Table 5: Overcharge estimates and biases

\begin{tabular}{lcccccc}
\hline & & \multicolumn{3}{c}{ Overcharge estimate } & \multicolumn{2}{c}{ Overcharge bias } \\
& Obs. & Pre-Cartel & Post-Cartel & Whole sample & Post-Cartel & Whole sample \\
\hline Comm & 6 & 64.45 & 19.91 & 41.12 & $-77.75 \%$ & $-40.73 \%$ \\
Fine & 2 & 55.41 & 10.73 & 32.01 & $-68.01 \%$ & $-35.62 \%$ \\
Leniency & 4 & 48.91 & 8.82 & 27.91 & $-20.30 \%$ & $-10.63 \%$ \\
ExtComm & 7 & 46.89 & 22.12 & 33.91 & $-24.67 \%$ & $-12.92 \%$ \\
\hline Pooled & 19 & 53.76 & 17.42 & 34.72 & $-45.07 \%$ & $-23.61 \%$ \\
\hline MRemoval & 5 & 40.63 & 53.86 & 47.25 & $129.73 \%$ & $64.87 \%$ \\
\hline
\end{tabular}

Notes: Pre-Cartel, Post-Cartel, and Whole sample overcharge estimates represent average values of estimated cummulated cartel overcharges by cartel based on competitive price benchmarks including periods before, after, and before and after the cartel. Pre-cartel prices serve as the counterfactuals for the calculation of overcharges biases. Pooled includes the average values of the columns excluding the MRemoval treatment.

Table 5 contains the average of the estimated cartel overcharges using the different benchmark prices in the first three columns by treatment. Prices before communication represent the true competitive counterfactual. Unlike Post-cartel prices, they are untainted by tacit collusion enabled by preceding communication. It follows that the Post-Cartel and Whole sample cartel overcharge estimates are biased. Columns IV and V contain the average overcharge bias. The results indicate that cartel overcharges are significantly biased downwards in all treatments except for the MRemoval treatment. In other words, tacit collusion enabled by preceding communication in cartels leads to significant levels of underestimation of cartel damages in econometric techniques relying on post-cartel data. Note that it is not possible to rank the treatments of this study with respect to severity of the downward bias due to the limited sample size. The problem of underestimating cartel damages does not exist in the MRemoval treatment,

Baseline treatment is not a suitable benchmark for the calculation of the cartel overcharge, and we use only the ExtComm treatment for the benchmark price. 
Figure 5: Post-cartel overcharge bias by cartel success

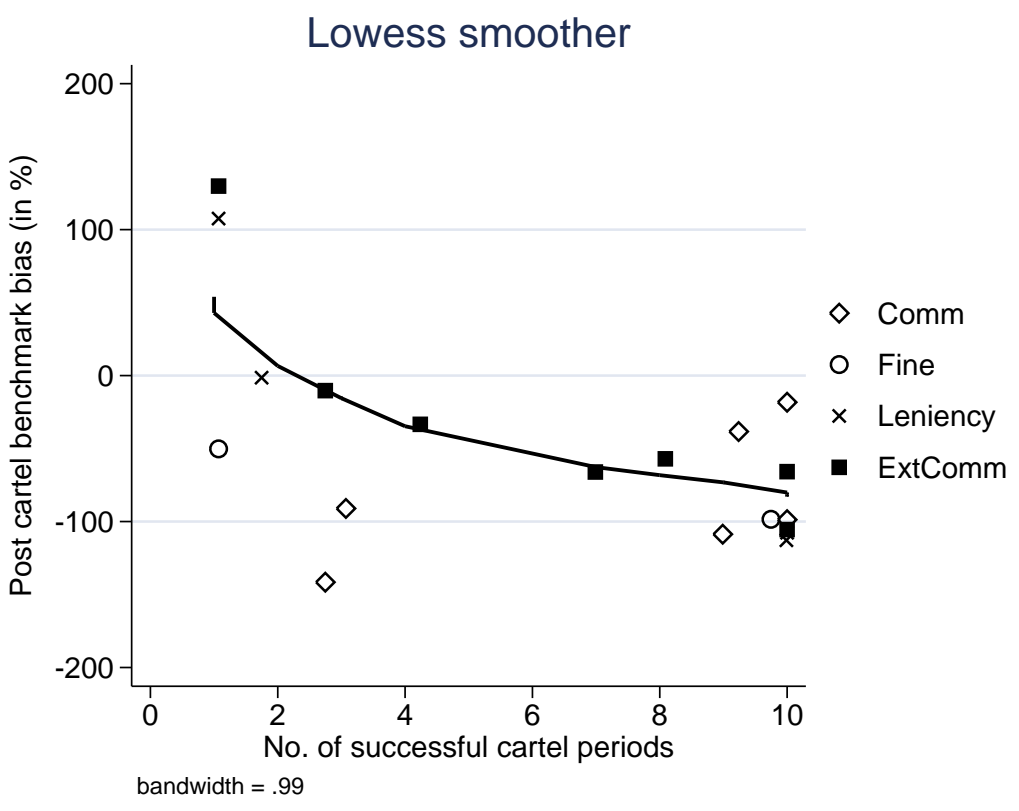

as there is virtually no tacit collusion in this treatment. ${ }^{19}$ As has been shown in the theoretical model, post-cartel prices might be a function of preceding cartel success. As such, the downward bias of estimates should be increasing with the number of preceding cartel success. Econometric evidence for this observation is presented in Table 4.

Result 5: The downward bias in damage estimates based on the before-after approach increases with preceding cartel success without the removal of managers.

The result of the overcharge bias estimations can be plotted to illustrate Result 5 . Figure 5 depicts the relationship between the post-cartel approach biases and the number of successful cartel periods with a lowess smoother excluding the MRemoval treatment. Indeed, on average, the downward bias is increasing with preceding cartel success. ${ }^{20}$ Thus, the results illustrate that indeed it may be the most harmful cartels that are deterred the least by private damages provided that price benchmarks based on prices of the convicted party are used.

\section{Conclusion}

Although it is conventional wisdom that firms might resort to tacit collusion after cartels, little is known under which conditions this happens and which determinants drive the level and persistence of PCTC. As a result, it is hard to assess implications of such firm behavior for

\footnotetext{
${ }^{19}$ In fact, the estimations point to a large overestimation of damages in this treatment. However, these results should be treated with caution, as the competitive counterfactual of ExtComm prices in periods -9 to 0 might not be good counterfactuals for MRemoval. Given the destabilizing effect of informing about the potential manager removal in the future on collusion, a proper counterfactual for this treatment would likely contain lower prices.

${ }^{20}$ The observations for the Comm treatment show two outliers not in line with this functional relationship. However, given the small number of observations, these outlier should not receive too much attention. Further, note that the overcharge estimates in Figure 5 are jittered to improve readability.
} 
competition policy and how to counteract it. Given the importance of PCTC for deterrent fines, welfare effects of cartels, and the right design of antitrust legislation, this paper aims at adding to the knowledge on the existence, determinants, consequences, and prevention of PCTC.

We run experiments in which groups of three firms compete in homogeneous goods Bertrand competition and can agree to fix prices for a limited number of periods. After this initial phase of communication, the ability to agree on price fixing ends and firms are able to collude only tacitly. Such an approach contributes to our understanding on how cartels react to detection provided that firms stop to communicate. We test the existence of PCTC in different competition regimes to establish whether it is a common phenomenon unrelated to particular policy tools. Guidance on the determinants of PCTC is derived from a simple theoretical model, in which firms' expectations about the other firms' intention to collude depends on the collusive history of the industry. In the model the probability and magnitude of tacit collusion increases with preceding cartel success. The removal of cartel managers as a means to disrupt collusion is tested.

The results suggest that firms might frequently be able to profit from PCTC, and they show that it does not depend on specific antitrust laws. We identify two sources of PCTC: collusive price hysteresis and learning in cartels. The former describes firm's strategy to continue charging preceding cartel prices after the end of the cartel in order to avoid triggering a price war resulting in the reversion of the industry to the lower competitive prices, and the latter describes how communication and a cooperative history facilitate PCTC by reducing uncertainty. Further, the magnitude of PCTC is positively linked to preceding cartel success. In line with Bigoni et al. (2015), this stresses the importance of beliefs for successful collusion in infinitely repeated games. The removal of managers after cartel detection as emulated by rematching in the experiment is found to be an effective mechanism preventing PCTC as well as reducing cartel stability in the experiment. Therefore, criminal sanctions leading to the removal of convicted managers are an effective measure to reduce cartel duration, and increase deterrence even in the absence of other antitrust sanctions such as fines or leniency programs. Complementary research suggests that PCTC might primarily arise in oligopolies with few firms, and that a larger number of firms in the market renders collusion without renewed communication increasingly difficult (Davies et al., 2011; Fonseca and Normann, 2012, 2014).

Several implications arise. Antitrust laws that reduce the formation and stability of cartels lessen the negative welfare effects of PCTC, as the incidence of tacit collusion is primarily triggered by preceding cartelization of the industry. Cartels that do not break down due to cheating but are detected exogenously might realize supercompetitive profits long after the end of communication. Therefore, competition agencies should rely both on leniency programs and criminal sanctions for cartel managers to minimize the harm caused by PCTC. Yet, a potentially important principal agency problem arises that is not well understood. Firms could rely on "inverted entity liability" to undermine the effectiveness of debarment (Robson, 2010). If senior managers delegate the operation of a cartel to junior managers and deny any 
knowledge of the antitrust infringement, there is the risk that convicted junior managers are merely replaced with new managers receiving the same instructions from the senior management. Therefore, the removal of managers is only an effective policy against PCTC if the true authors of the antitrust conspiracy are targeted. Moreover, cartel deterrence might not be guaranteed as fines are based on periods with communication only. Continuing levels of tacit collusion after the end of communication might increase the number of cartels, in particular if firms understand cartels as a means to establish tacit collusion and anticipate higher post-cartel profits in the formation decision. In addition, in these cases post-cartel prices should not be used as competitive counterfactuals to determine cartel overcharges. Results suggest that the downward bias in these estimates also increases with preceding cartel success. As such, the most harmful cartels might be those least deterred. This provides another explanation on the significant level of cartel recidivism observed in the last two decades.

A possible caveat of this study is the focus on learning as a source of PCTC abstracting from focal points in the spirit of Scherer (1967) as a source of collusion: after the removal of convicted cartel managers, new managers could try to establish tacit collusion by setting the price last charged by the cartel to keep up collusion. This could facilitate PCTC provided there is inverted entity liability strategies implemented by senior managers. This is an area of research that should receive more attention. Knowledge on the dynamics of cartel pricing is still sparse, which limits our understanding of factors facilitating PCTC. In this respect, the effects of variations of market characteristics other than firm numbers as well as product differentiation on PCTC should be studied. 


\section{References}

Apesteguia, J., Dufwenberg, M. and Selten, R. (2007). Blowing the whistle. Economic Theory, 31 (1), 143-166.

Belleflamme, P. and Peitz, M. (2010). Industrial organization: markets and strategies. Cambridge University Press.

Bigoni, M., Fridolfsson, S.-O., Le Coq, C. and Spagnolo, G. (2012). Fines, leniency, and rewards in antitrust. The RAND Journal of Economics, 43 (2), 368-390.

—, - - - and Spagnolo, G. (2015). Trust, Leniency and Deterrence. Journal of Law, Economics and Organization, Forthcoming.

Borenstein, S. (2004). Rapid price communication and coordination: The airline tariff publishing case (1994). In J. E. Kwoka and L. J. White (eds.), The Antitrust Revolution: Economics, Competition, and Policy: 4h Edition, Oxford: Oxford University Press, pp. 233-251.

Bresnahan, T. F. and Reiss, P. C. (1991). Entry and Competition in Concentrated Markets. Journal of Political Economy, 99 (5), 977-1009.

Bryant, P. G. and Eckard, E. W. (1991). Price fixing: the probability of getting caught. The Review of Economics and Statistics, 73 (3), 531-536.

CAson, T. N. (1995). Cheap talk price signaling in laboratory markets. Information Economics and Policy, 7 (2), 183-204.

Chamberlin, E. H. (1933). The Theory of Monopolistic Competition. Cambridge, MA: Harvard University Press.

Chowdhury, S. M. and Wandschneider, F. (2013). Anti-trust and the 'Beckerian Proposition': the Effects of Investigation and Fines on Cartels. Centre for Competition Policy Working Paper No. $13-9$.

— and - (2014). An Experimental Analysis of Anti-trust Enforcement under Avoidance. Mimeo.

Connor, J. M. (1998). The global citric acid conspiracy: Legal-economic lessons. Agribusiness, 14 (6), 435-452.

- (2001). "Our Customers Are Our Enemies": The Lysine Cartel of 1992-1995. Review of Industrial Organization, 18 (1), 5-21.

Crede, C. J. and Lu, L. (2015). The effect of endogenous fines and detection probabilities on cartel formation and prices. Mimeo.

DAL Bó, P. (2005). Cooperation under the shadow of the future: experimental evidence from infinitely repeated games. American Economic Review, 95 (5), 1591-1604.

Davies, S., Olczak, M. and Coles, H. (2011). Tacit collusion, firm asymmetries and numbers: Evidence from EC merger cases. International Journal of Industrial Organization, 29 (2), 221-231.

Davies, S. W., Ormosi, P. L. and Graffenberger, M. (2014). Mergers after cartels: How markets react to cartel breakdown. Centre for Competition Policy Working Paper No. 14-1.

Davis, D., Korenok, O. and Reilly, R. (2009). Re-matching, information and sequencing effects in posted offer markets. Experimental Economics, 12 (1), 65-86.

—, - and - (2010). Cooperation without coordination: signaling, types and tacit collusion in laboratory oligopolies. Experimental Economics, 13 (1), 45-65. 
Davis, P. and GarcÉs, E. (2009). Quantitative techniques for competition and antitrust analysis. Princeton: Princeton University Press.

Dufwenberg, M. and Gneezy, U. (2000). Price competition and market concentration: an experimental study. International Journal of Industrial Organization, 18 (1), 7-22.

Erutku, C. (2012). Testing post-cartel pricing during litigation. Economics Letters, 116 (3), 339-342.

FischBACHER, U. (2007). z-Tree: Zurich toolbox for ready-made economic experiments. Experimental Economics, 10 (2), 171-178.

Fonseca, M. A. and Normann, H.-T. (2012). Explicit vs. tacit collusion-The impact of communication in oligopoly experiments. European Economic Review, 56 (8), 1759-1772.

- and - (2014). Endogenous cartel formation: Experimental evidence. Economics Letters, 125 (2), $223-225$.

Foster, D. P. and Young, H. (2003). Learning, hypothesis testing, and Nash equilibrium. Games and Economic Behavior, 45 (1), 73-96.

Gillet, J., Schram, A. and Sonnemans, J. (2011). Cartel formation and pricing: The effect of managerial decision-making rules. International Journal of Industrial Organization, 29 (1), 126-133.

Ginsburg, D. H. and Wright, J. D. (2010). Antitrust Sanctions. Competition Policy International, $6(2)$.

Greimel, H. (2014). Confessions of a price fixer: Supplier network shelters fugitives, ex-cons. Automotive News. Available online on 11/16/2014 at http://www.autonews.com/article/20141116/OEM10/311179961/confessions-of-a-price-fixer. Last accessed 08/06/2015.

Greiner, B. (2004). An Online Recruitment System for Economic Experiments. In K. Kremer and V. Macho (eds.), Forschung und wissenschaftliches Rechnen 2003, Goettingen: GWDG, pp. 79-93.

Hamaguchi, Y., Kawagoe, T. and Shibata, A. (2009). Group size effects on cartel formation and the enforcement power of leniency programs. International Journal of Industrial Organization, $27(2), 145-165$.

Harrington, J. E. (2004). Post-cartel Pricing during Litigation. Journal of Industrial Economics, $\mathbf{5 2}(4), 517-533$.

- (2012). A Theory of Tacit Collusion. Johns Hopkins University Department of Economics Working Paper Archive No. 588.

Hinloopen, J. and Onderstal, S. (2014). Going once, going twice, reported! Cartel activity and the effectiveness of antitrust policies in experimental auctions. European Economic Review, 70, 317-336.

- and Soetevent, A. R. (2008). Laboratory evidence on the effectiveness of corporate leniency programs. The RAND Journal of Economics, 39 (2), 607-616.

Holt, C. A. and Davis, D. (1990). The effects of non-binding price announcements on posted-offer markets. Economics Letters, 34 (4), 307-310.

- and Laury, S. K. (2002). Risk Aversion and Incentive Effects. The American Economic Review, 92 (5), 1644-1655.

Huck, S., Normann, H.-T. and Oechssler, J. (2004). Two are few and four are many: number effects in experimental oligopolies. Journal of Economic Behavior 83 Organization, 53 (4), 435-446. 
IsAAC, R. M. and WALKeR, J. M. (1988). Communication and free-riding behavior: The voluntary contribution mechanism. Economic Inquiry, 26 (4), 585-608.

Ivaldi, M., Jullien, B., Rey, P., Seabright, P. and Tirole, J. (2003). The economics of tacit collusion. IDEI Working Paper No. 186.

Kovacic, W. E., Marshall, R. C., Marx, L. M. and Raiff, M. E. (2007). Lessons for Competition Policy from the Vitamins Cartel. Contributions to Economic Analysis, 282, 149-176.

KwokA, J. E. (1979). The Effect of Market Share Distribution on Industry Performance. The Review of Economics and Statistics, 61 (1), 101-109.

Lande, R. H. and Davis, J. P. (2008). Benefits from private antitrust enforcement: An analysis of forty cases. University of San Francisco Law Review, 42, 879.

Martin, S. (2006). Competition policy, collusion, and tacit collusion. International Journal of Industrial Organization, 24 (6), 1299-1332.

Motta, M. and Polo, M. (2003). Leniency programs and cartel prosecution. International Journal of Industrial Organization, 21 (3), 347-379.

Mouraviev, I. (2006). Private Observation, Tacit Collusion and Collusion with Communication. IFN Working Paper No. 672.

Mundlak, Y. (1978). On the Pooling of Time Series and Cross Section Data. Econometrica, 46 (1), 69-85.

Ordóñez-De Haro, J. M. and Torres, J. L. (2014). Price hysteresis after antitrust enforcement: Evidence from spanish food markets. Journal of Competition Law and Economics, 10 (1), 217-256.

Rabin, M. (1993). Incorporating Fairness into Game Theory and Economics. The American Economic Review, 83 (5), 1281-1302.

Robson, R. A. (2010). Crime and Punishment: Rehabilitating Retribution as a Justification for Organizational Criminal Liability. American Business Law Journal, 47 (1), 109-144.

Roos, N. D. (2006). Examining models of collusion: The market for lysine. International Journal of Industrial Organization, 24 (6), 1083-1107.

Scherer, F. M. (1967). Focal point pricing and conscious parallelism. Antitrust Bulletin, 12, 495.

Vermeulen, A. J., Am Bos and Letterie, W. A. (2013). Antitrust as facilitating factor for collusion. Mimeo.

Wellford, C. (2002). Antitrust, results from the laboratory. In C. A. Holt and R. Isaac (eds.), Experiments investigating market power, Amsterdam: JAI Elsevier, pp. 1-60.

WiLs, W. P. J. (2003). Should private antitrust enforcement be encouraged in Europe? World Competition: Law and Economics Review, 26 (3).

Wooldridge, J. M. (2010). Econometric analysis of cross section and panel data. MIT press, 2nd edn.

Young, H. P. (2007). The possible and the impossible in multi-agent learning. Artificial Intelligence, 171 (7), 429-433. 


\section{Appendix A: Model}

Without loss of generality, suppose that there are 2 profit-maximizing firms denoted with index $i$. Both firms can simultaneously either set a high price $P_{h}$ or a low price $P_{l}$. If they set price $P_{h}$ a collusive market outcome is achieved and each of them realizes profits of $\Pi^{m}$. However, if both firms set price $P_{l}$, they receive a competitive profit $\Pi^{n}$. If one firm sets $P_{h}$ and the other $P_{l}$, the firm wth the lower price receives a deviation profit of $\Pi^{d}$, whereas the other firm earn profit $\Pi^{c}$. Assume that the order of the profits represents a prisoner's dilemma situation, i.e., $\Pi^{d}>\Pi^{m}>\Pi^{n}>\Pi^{c}$. Therefore, in a static framework the dominant strategy of both firms is to set price $P_{l}$, such that the unique Nash equilibrium is $\left(P_{l}, P_{l}\right)$.

However, assume this is an infinitely repeated game. Denote the set of prices of firm $i$ in period $t$ as action $a_{i t} \in\left\{P_{l}, P_{h}\right\}$ and the resulting action profile including both firms as $a_{t}=\left(a_{1 t}, a_{2 t}\right)$. The action profile induces payoffs $\Pi_{i t}\left(a_{t}\right)$ for both firms. The present value of the cumulated profits at time $t$ given the discount factor $\delta$ are $\Pi_{i}=\sum_{t=1}^{\infty} \delta_{i}^{t-1} \Pi_{i t}$.

Both firms continuously incorporate new information in the form of the most recent action pairs into the choice of their actions. The ex-post information about all actions are captured in histories, which are a sequence of strategy pairs, $h_{t}=\left(a_{1}, \ldots, a_{t-1}\right)$. The set of all histories is denoted with $H$. In $t=1$ the history is empty with $h_{1}=(\varnothing)$. The history is used to derive actions with plans of actions, $\Omega\left(h_{t}\right)$. Each plan of action specifies the action that is chosen for each history, $\Omega\left(h_{t}\right) \in\left\{P_{l}, P_{h}\right\} \forall h_{t} \in H$. Assume that there are two plans of actions that the firms can take: They can either try to collude or engage in competition. Plan of action $\mathrm{N}$ is non-collusive and indicates that a low price is always set, irrespective of the history. Thus, $N\left(h_{t}\right)=P_{l} \forall h_{t}$. Plan of action $\mathrm{C}$ is a collusive plan, which results in a firm to set a collusive price until another firm sets a low price, i.e., a grim trigger strategy is used to support collusion. This yields

$$
C\left(h_{t}\right)= \begin{cases}P_{h}, & \text { if } P_{l} \notin h_{t}\left(a_{t}\left(P_{l}, P_{h}\right)\right) \forall t \\ P_{l}, & \text { otherwise. }\end{cases}
$$

The plans of actions employed by both firms result in a realized pair of actions $a_{t}=\left(a_{1 t}, a_{2 t}\right)$ which determines profits $\Pi_{i t}\left(P_{1 t}, \ldots, P_{n t}\right)=\sum_{t=1}^{\infty} \delta^{t-1} \Pi_{i t}\left(a_{t}\right)$. The plans of actions result in two strategies for each firm, $s_{i}=\left(s_{i C}, s_{i N}\right)$, that is they can either try to collude or engage in competition.

Expectations of firm $i$ with regards to firm $j$ playing strategy $a_{j C}$ and $a_{j N}$ are characterized by probabilities $\lambda_{i t}$ and $\left(1-\lambda_{i t}\right)$, respectively.

Strategies therefore combine information about the history and expectations with respect to cheating by the opponent into actions, $s_{i C}: H \rightarrow\left\{P_{l}, P_{h}\right\}$ and $s_{i N}: H \rightarrow\left\{P_{l}, P_{h}\right\}$. $s_{i C}\left(h_{t}\right) \in\left\{P_{l}, P_{h}\right\}$ if cheating is not expected and $s_{i N}\left(h_{t}\right) \in\left\{P_{l}, P_{h}\right\}$ when cheating by others is 
expected.

The payoffs of firm $i$ depend on both its own strategy as well as that of firm $j$. However, as firm $i$ cannot predict the strategy of firm $j$, it has to base its decisions on expected payoffs.

$$
V_{1 C}\left(s_{1}, s_{2}\right)=\lambda_{1 t} \Pi_{1}\left(s_{1 C}, s_{2 C}\right)+\left(1-\lambda_{1 t}\right) \Pi_{1}\left(s_{1 C}, s_{2 N}\right)
$$

The other three possible expected profits $V_{1 N}\left(s_{1}, s_{2}\right), V_{2 C}\left(s_{1}, s_{2}\right)$, and $V_{2 N}\left(s_{1}, s_{2}\right)$ can be defined similarly.

Here, a Bayesian Nash Equilibrium is a pair of strategies $\left(s_{1}, s_{2}\right)$, in which

$$
\begin{aligned}
& V_{1 C}\left(s_{1}, s_{2}\right) \geq V_{1 C}\left(\widetilde{s}_{1}, s_{2}\right) \text { and } V_{1 N}\left(s_{1}, s_{2}\right) \geq V_{1 N}\left(\widetilde{s}_{1}, s_{2}\right) \text { for firm } 1 \\
& V_{2 C}\left(s_{1}, s_{2}\right) \geq V_{2 C}\left(\widetilde{s}_{1}, s_{2}\right) \text { and } V_{2 N}\left(s_{1}, s_{2}\right) \geq V_{2 N}\left(\widetilde{s}_{1}, s_{2}\right) \text { for firm } 2,
\end{aligned}
$$

with $\widetilde{s}_{1}$ and $\widetilde{s}_{2}$ denoting all available strategies of firms 1 and 2 , respectively. 


\section{Appendix B: Tables}

Table 6: Asking prices by phase - MWU test p-value matrix

\begin{tabular}{lccccc}
\hline & Comm & Fines & Leniency & ExtComm & MRemoval \\
\hline Communication phase & & & & & \\
Baseline & 0.000 & 0.000 & 0.000 & 0.000 & 0.000 \\
Comm & & 0.000 & 0.000 & 0.649 & 0.007 \\
Fine & & & 0.278 & 0.000 & 0.000 \\
Leniency & & & 0.000 & 0.000 \\
ExtComm & & & & 0.001 \\
\hline No Communication phase & 0.000 & 0.278 & 0.526 & 0.000 & 0.000 \\
Baseline & & 0.000 & 0.000 & 0.004 & 0.000 \\
Comm & & & 0.650 & 0.000 & 0.005 \\
Fine & & & & 0.000 & 0.004 \\
Leniency & & & & & 0.267 \\
ExtComm & & & & \\
\hline
\end{tabular}

Notes: Periods 1-10 are used for the Baseline treatment in the comparison of market prices in the No Communication phase.

Table 7: Proportion of cartelized markets - Fisher's exact test p-value matrix

\begin{tabular}{lcccc}
\hline & Fines & Leniency & ExtComm & MRemoval \\
\hline Comm & 0.000 & 0.000 & 0.293 & 1.000 \\
Fine & & 0.290 & 0.000 & 0.000 \\
Leniency & & & 0.000 & 0.000 \\
ExtComm & & & & 0.255 \\
\hline
\end{tabular}

Notes: P-values are based on two-sided Fisher's exact tests.

Table 8: Proportion of cheating in makets - Fisher's exact test p-value matrix

\begin{tabular}{lcccc}
\hline & Fines & Leniency & ExtComm & MRemoval \\
\hline Comm & 0.469 & 1.000 & 0.315 & 0.000 \\
Fine & & 0.423 & 1.000 & 0.051 \\
Leniency & & & 0.307 & 0.001 \\
ExtComm & & & & 0.004 \\
\hline
\end{tabular}

Notes: P-values are based on two-sided Fisher's exact tests. 
Table 9: Prices in the No Communication periods - Random Effects model

\begin{tabular}{|c|c|c|c|c|}
\hline \multirow[b]{3}{*}{ Baseline: Baseline } & I & II & III & IV \\
\hline & \multicolumn{2}{|c|}{ Asking price } & \multicolumn{2}{|c|}{ Market price } \\
\hline & $\begin{array}{l}\text { Coeff. } \\
\text { (Std.E.) }\end{array}$ & $\begin{array}{l}\text { Coeff. } \\
\text { (Std.E.) }\end{array}$ & $\begin{array}{l}\text { Coeff. } \\
\text { (Std.E.) }\end{array}$ & $\begin{array}{l}\text { Coeff. } \\
\text { (Std.E.) }\end{array}$ \\
\hline \multirow[t]{2}{*}{ Lag price } & $0.544^{\dagger}$ & $0.479^{\dagger}$ & $0.734^{\dagger}$ & $0.372^{\dagger}$ \\
\hline & $(0.040)$ & $(0.053)$ & $(0.057)$ & $(0.109)$ \\
\hline \multirow[t]{2}{*}{ Lag other players' prices } & $0.240^{\dagger}$ & $0.173^{* * *}$ & - & - \\
\hline & $(0.035)$ & $(0.059)$ & & \\
\hline \multirow[t]{2}{*}{ Lag collusion } & $1.308^{\dagger}$ & $2.740^{\dagger}$ & $2.042^{\dagger}$ & $6.260^{\dagger}$ \\
\hline & $(0.330)$ & $(0.479)$ & $(0.554)$ & $(1.220)$ \\
\hline \multirow[t]{2}{*}{ No. of successful cartel periods } & $0.258^{* * *}$ & $0.981^{\dagger}$ & $0.294^{* *}$ & 0.245 \\
\hline & $(0.099)$ & $(0.253)$ & $(0.117)$ & $(0.455)$ \\
\hline \multirow{2}{*}{ Period } & 0.039 & 0.042 & 0.000 & -0.025 \\
\hline & $(0.032)$ & $(0.072)$ & $(0.027)$ & $(0.051)$ \\
\hline \multirow{2}{*}{$\begin{array}{l}\text { Period } \times \text { No. of } \\
\text { successful cartel periods }\end{array}$} & $-0.012^{* *}$ & $-0.050^{* * *}$ & $-0.016^{* *}$ & -0.009 \\
\hline & $(0.006)$ & $(0.017)$ & $(0.006)$ & $(0.032)$ \\
\hline \multirow[t]{2}{*}{ Comm } & 0.144 & - & 0.069 & - \\
\hline & $(0.317)$ & & $(0.310)$ & \\
\hline \multirow[t]{2}{*}{ Fine } & 0.154 & - & 0.084 & - \\
\hline & $(0.314)$ & & $(0.284)$ & \\
\hline \multirow[t]{2}{*}{ Leniency } & -0.018 & - & -0.160 & - \\
\hline & $(0.275)$ & & $(0.219)$ & \\
\hline \multirow[t]{2}{*}{ ExtComm } & $-0.521^{*}$ & - & -0.294 & - \\
\hline & $(0.298)$ & & $(0.232)$ & \\
\hline \multirow[t]{2}{*}{ Constant } & $19.380^{\dagger}$ & $31.851^{\dagger}$ & $24.451^{\dagger}$ & $57.925^{\dagger}$ \\
\hline & (3.998) & $(4.806)$ & $(5.285)$ & $(9.928)$ \\
\hline$R^{2}$ overall & 0.705 & 0.432 & 0.863 & 0.579 \\
\hline$R^{2}$ between & 0.963 & 0.907 & 0.982 & 0.961 \\
\hline$R^{2}$ within & 0.125 & 0.181 & 0.401 & 0.393 \\
\hline Observations & 1,674 & 378 & 558 & 126 \\
\hline
\end{tabular}

Notes: $* 10 \%$ level, $* * 5 \%$ level, $* * * 1 \%$ level, $\dagger 0.1 \%$ level. - Cluster and autocorrelation-robust standard errors in parentheses. - Columns I and III contain observations for all treatments except for MRemoval, and Columns I and IV are based on MRemoval treatment observations only. - All estimations are based on RE regressions. 


\section{Appendix C: Instructions (Leniency)}

\section{Instructions}

Welcome and thank you for taking part in this experiment. In this experiment you can earn money. How much money you will earn depends on your decision and on the decision made by other participants in this room. The experiment will proceed in two parts. The currency used in Part 1 of the experiment is Pound Sterling (GBP). The currency used in Part 2 is experimental points. Each experimental point is worth 15 pence. All earnings will be paid to you in cash at the end of the experiment.

Every participant receives exactly the same instructions. All decisions will be anonymous. It is very important that you remain silent. If you have any questions, or need assistance of any kind, please raise your hand and an experimenter will come to you.

\section{Instructions for Part 1}

In the first part of the experiment you will be asked to make 15 decisions. For each line in the table that you will see on the computer screen there is a paired choice between two options ("Option A" and "Option B"). Only one of these 15 lines will be used in the end to determine your earnings. You will only know which one at the end of the experiment. Each line is equally likely to be chosen, so you should pay equal attention to the choice you make in every line. At the end of the experiment a computerized random number (between 1 and 15) determines which line is going to be paid.

Your earnings for the paid line depend on which option you chose: If you chose Option A in that line, you will receive $£ 1$. If you chose Option B in that line, you will receive either $£ 2$ or $£ 0$. To determine your earnings in the case you chose Option B there will be second computerized random number (between 1 and 20). Both computerized random numbers will be the same for all participants in the room.

\section{Instructions for Part 2}

In this part of the experiment you will form a group with two other randomly chosen participants in this room. Throughout the experiment you are matched with the same two participants. All groups of three participants act independently of each other. This part of the experiment will be repeated for at least 20 rounds. From the 20 th round onwards, in each round there is a one in five $(\mathbf{2 0 \%})$ chance that the experiment will end.

Your job:

You are in the role of a firm that is in a market with two other firms. In each round, you will have to choose a price for your product. This price must be one of the following prices:

90, 91, 92, 93, 94, 95, 96, 97, 98, 99, 100, 101, 102.

You will only sell the product if your price is the lowest of the three prices chosen by you and the other two firms in that round. If you sell the product, your earnings are equal to the difference 
between the price and the cost, which is 90 :

\section{Earnings $=$ Price -90.}

If you do not sell the product, you will not get any earnings but you will not incur costs either. If two or more firms sell at the same lowest price, the earnings will be shared equally between them. Before you choose your price, you may decide to agree with the other firms to set the highest price of $\mathbf{1 0 2}$ and share the earnings. This agreement is only valid if all three firms want to agree on it. After you made your choice, you will be informed whether the price agreement is reached. However, the price agreement is not binding and firms are not required to set the agreed price. After your price choice, you will be told whether you have selected the lowest price as well as the prices of the other firms.

The price agreement may be discovered by the computer. In that case, a fine of $\mathbf{5}$ points has to be paid. The computer can detect it in 16 out of 100 cases (a chance of 16\%). A price agreement remains valid - and can be discovered - as long as it has not been discovered in a previous round. Once this has happened, you will not be fined in the future, unless you make a price agreement again. If you have reached a price agreement in this period, or a past agreement has not been detected by the computer, you must decide whether to report it. You can do this by choosing between the "Report" and "Not report" buttons. If you report it, you are charged additional costs of 1 .

In case one or more group members reports the agreement, it is discovered and a penalty of $\mathbf{5}$ has to be paid by all group members. However, in case you report your penalty gets reduced as follows:

- If you are the only one to report, you will not pay the penalty but the others will pay the full penalty.

- If you report and exactly one of the other two reports, then your penalty is reduced by half $(50 \%)$. The other reporting participant has to pay only half of his penalty, while the remaining participant will pay his full penalty.

- If you report and both the other two also report, then the penalty is reduced by one third $(33 \%)$ for all three of you.

At the end of each round, you will be told the earnings you made in this round. If you agreed on prices, you will also be told whether the agreement was detected by the computer (either because it was detected by chance or by reports).

\section{Final Payment:}

At the beginning of the experiment you start with an initial endowment of 40 points $=6$ GBP. If the sum of your profits from Part B is below 0, the difference is being covered by the initial endowment. The earnings you earned in each round minus any fine and penalty that you paid will be converted into cash. Each point is worth 15 pence, and we will round up the final payment to the next 10 pence. We guarantee a minimum earning of 2 GBP. 